\title{
Environmental Enrichment Confers Stress Resiliency to Social Defeat through an Infralimbic Cortex-Dependent Neuroanatomical Pathway
}

\author{
Michael L. Lehmann and Miles Herkenham \\ Section on Functional Neuroanatomy, Laboratory of Cellular and Molecular Regulation, National Institute of Mental Health, National Institutes of Health, \\ Bethesda, Maryland 20892
}

Enriched environmental (EE) housing dampens stress-induced alterations in neurobiological systems, promotes adaptability, and extinguishes submissive behavioral traits developed during social defeat stress (SD). In the present study, we hypothesized that enrichment before SD can confer stress resiliency and, furthermore, that neuronal activity in the prefrontal cortex (PFC) is requisite for this resiliency. To test these hypotheses, mice were housed in EE, standard (SE), or impoverished (IE) housing and then exposed to SD. EE conferred resilience to SD as measured in several behavioral tasks. EE-housed mice expressed elevated FosB/ $\Delta$ FosB immunostaining in areas associated with emotional regulation and reward processing, i.e., infralimbic, prelimbic, and anterior cingulate cortices, amygdala, and nucleus accumbens, and this expression was mostly preserved in mice receiving EE followed by SD. In contrast, in SE- or IE-housed animals, SD increased maladaptive behaviors and greatly reduced FosB/ $\Delta$ FosB staining in the forebrain. We tested the putative involvement of the PFC in mediating resilience by lesioning individual regions of the PFC either before or after EE housing and then exposing the mice to SD. We found that discrete lesions of the infralimbic but not prelimbic or cingulate cortex made before but not after EE abolished the behavioral resiliency to stress afforded by EE and attenuated FosB $/ \Delta$ FosB expression in the accumbens and amygdala while increasing it in the paraventricular hypothalamic nucleus. These data suggest that pathological ventromedial PFC outputs to downstream limbic targets could predispose an individual to anxiety disorders in stressful situations, whereas enhanced ventromedial PFC outputs could convey stress resilience.

\section{Introduction}

Resiliency-the ability to recover from adverse change-comprises psychological and biological processes that allow an individual to avoid or reduce the harmful consequences of extreme stress. Resilient individuals encountering chronic psychosocial stress minimize pathophysiological outcomes, e.g., extended or exaggerated hypothalamic-pituitary-adrenal (HPA) axis activity (McEwen and Stellar, 1993; Sapolsky, 2000), that can precipitate stress-related diseases such as posttraumatic stress disorder (PTSD), anxiety, and major depression (Kudryavtseva and Avgustinovich, 1998; Avgustinovich et al., 2005; Huhman, 2006). Although many studies focus on maladaptive responses to psychological stress, relatively little research has been directed toward understanding stress resilience and its etiology. The staggering prevalence of stress-related disorders underscores the need for

Received Feb. 2, 2011; accepted Feb. 26, 2011.

Author contributions: M.L.L. and M.H. designed research; M.L.L. performed research; M.L.L. and M.H. analyzed data; M.L.L. and M.H. wrote the paper.

This work was supported by the Intramural Research Program of the National Institute of Mental Health/National Institutes of Health. We thank Eric Holaday, Jay Levin, and Rebecca Brachman for technical assistance.

The authors declare no competing financial interests.

Correspondence should be addressed to Dr. Michael L. Lehmann, Section on Functional Neuroanatomy, Nationa Institute of Mental Health, Building 35, Room 1C911, 35 Convent Drive, Bethesda, MD 20892-3724. E-mail: Michael.Lehmann@nih.gov.

DOI:10.1523/JNEUROSCI.0577-11.2011

Copyright $\odot 2011$ the authors $\quad 0270-6474 / 11 / 316159-15 \$ 15.00 / 0$ innovative approaches to treatment. Development of stress resiliency paradigms in animals will facilitate discovery of buffers against the onset of stress-related disorders.

Behavioral and physiological responses to stress are influenced by genetic and environmental factors (Charney, 2004; Charney and Manji, 2004; Suomi, 2006; Krishnan et al., 2007; Feder et al., 2009). Enriched environments (EE), including physical exercise, are powerful environmental factors that mitigate deleterious stress effects on neurobiological systems and endocrine profiles, and promote stress adaptability in both humans (Luger et al., 1987; Wittert et al., 1996; Salmon, 2001; Southwick et al., 2005) and rodents (Greenwood and Fleshner, 2008; Schloesser et al., 2010). Thus, EE may provide a valid animal model for the etiological examination of resiliency. Although the protective effects of EE on stress-related mood disorders are well characterized, little is known about the functional alterations in brain circuits that form the basis for resiliency or how environmental factors modulate activity in these circuits.

Social defeat $(\mathrm{SD})$ - a paradigm with accepted ethological validity - is a model for the examination of stress-related disorders (Koolhaas et al., 1997; Kudryavtseva, 2000). Mice enduring repeated SD become subordinate, with maladaptive psychological and deleterious physiological consequences. We propose that experimental combination of EE and SD stress in mice can lead to insights about stress resilience with high translational value. We showed previously that, in adult mice, EE after SD stress can 
extinguish depressive-like and subordinate behaviors induced by SD (Schloesser et al., 2010). In the present study, we hypothesized that EE before SD stress can attenuate the development of maladaptive behaviors of defeated mice and block stress-induced alterations in activity within neuroanatomical circuits mediating the stress response.

We further hypothesized that biological and neuroanatomical alterations in the medial prefrontal cortex (mPFC) form the basis for resiliency conferred by enrichment. FosB $/ \Delta$ FosB immunohistochemistry was used to map functional alterations in $\mathrm{MPFC}$ and associated brain circuits to disclose how the brain responds to differential environmental manipulations established before SD exposure. The long half-life of $\Delta \mathrm{FosB}$, a truncated splice variant of FosB that progressively accumulates in repeatedly activated neurons (Chen et al., 1997; McClung et al., 2004; Perrotti et al., 2004), allows examination of neuronal activation resulting from chronic SD. We found that the manipulations profoundly altered neuronal activity in limbic, cortical, and striatal circuits. We further demonstrated with selective cortical lesions that the infralimbic (IL) area of the $\mathrm{mPFC}$ may be responsible for the acquisition of stress resiliency conferred by EE.

\section{Materials and Methods}

Animals

All animals used for the behavior and immunohistochemical experiments were male C57BL/6 mice (10-12 week old) obtained from National Institutes of Health/National Cancer Institute/ Division of Cancer Treatment (Frederick, $\mathrm{MD})$. Before differential housing, all animals were housed four per cage in a $12 \mathrm{~h}$ (9:00 P.M. to 9:00 A.M.) light/dark colony room with food and water provided ad libitum. The procedures described were conducted in accordance with the National Institutes of Health guidelines and were approved by the National Institute of Mental Health Institutional Animal Care and Use Committee.

\section{Experimental design}

Experiment 1: the ability of previous environmental enrichment to confer stress resiliency during exposure to chronic social stress-behavioral and anatomical studies. As depicted in Figure 1 , a $3 \times 2$ (housing $\times$ stress treatment) factorial design was used to study the ability of previous housing environments to insulate mice from the deleterious effects of SD stress. Animals were singly housed either in enriched (EE), standard (SE), or impoverished (IE) housing environment for $21 \mathrm{~d}$. After $21 \mathrm{~d}$ of differential housing, animals were then randomly divided; one-half remained within their respective housing environment [home-cage (HC) housing], and the other half was placed into social conflict housing (procedure detailed below) to produce SD stress. After $14 \mathrm{~d}$ of social conflict or home-cage housing, mice were either behaviorally phenotyped for anxiety and depressive-like behaviors (Fig. 1) or processed for histological analysis (see below). The first experiment addresses the hypothesis that environmental enrichment can protect against the deleterious effects of chronic social defeat. To show causality and to determine whether IE before SD produces a negative outcome or to determine whether EE before SD produces a positive outcome, both groups were compared with animals housed in a standard housed control cage.
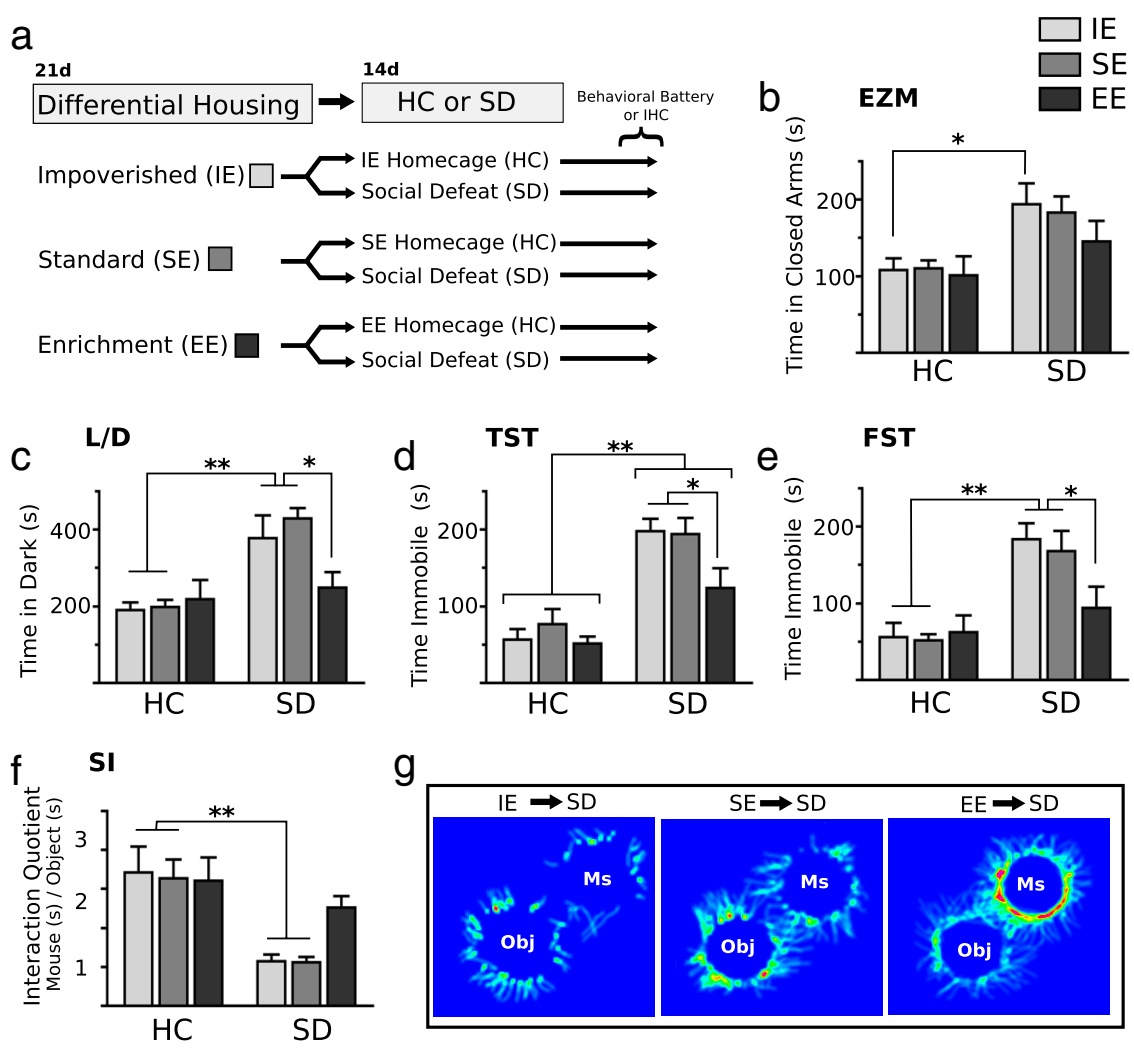

Figure 1. Previous exposure to environmental enrichment insulates mice from the deleterious effects of social defeat stress. $\boldsymbol{a}$, Diagram 列 more time and showed a significant increase in preference for interacting with the aggressor mouse $(\boldsymbol{f}, \boldsymbol{g})$. Ms, Mouse; Obj, object. Results are expressed as mean \pm SEM ( $n=8$ per group). For $\boldsymbol{b}-\boldsymbol{f}$, two-way ANOVA was followed by Bonferroni's post hoc test. Bonferroni's test: ${ }^{*} p<0.05 ;{ }^{* *} p<0.01$.

Experiment 2: role of the infralimbic cortex in the acquisition and expression of stress resiliency after exposure to environmental enrichment. As depicted in Figure $4 a$, the second study examined the connection between IL cortical processing of EE exposure and concomitant stress resiliency displayed by mice after EE housing. Using a $2 \times 3$ (infusion treatment $\times$ housing treatment) factorial design, mice were randomly divided into six treatment groups. One group of mice received either bilateral ibotenic acid lesions of the infralimbic cortex or sham control infusions of vehicle before placement in EE housing for $21 \mathrm{~d}$. After EE housing, mice were exposed to chronic social defeat for $14 \mathrm{~d}$, after which they were either phenotyped for anxiety and depressive-like behaviors or processed for histology (see below). A second control group of mice received bilateral infralimbic cortex infusions of ibotenic acid or vehicle $1 \mathrm{~d}$ before $35 \mathrm{~d}$ exposure to EE. After 35 d of EE, mice were either phenotyped or processed for histology. This non-defeat group was designed to control for the effect of social defeat and to examine the effect of infralimbic infusions on displays of affective behavioral disorders. A third group of mice was given a $21 \mathrm{~d}$ exposure to EE before receiving bilateral ibotenic acid or vehicle control infusions directed toward the infralimbic cortex. These mice were then exposed to $14 \mathrm{~d}$ of SD, after which they were either phenotyped for anxiety and depressive-like behaviors (see Fig. 4) or processed for histology (see Figs. 5, 6).

By design, the experiment asked three questions. First, does excitotoxic lesion of the infralimbic cortex affect baseline anxiety-like or depressive-like 
EE only

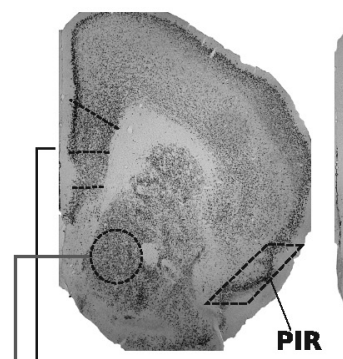

IE only
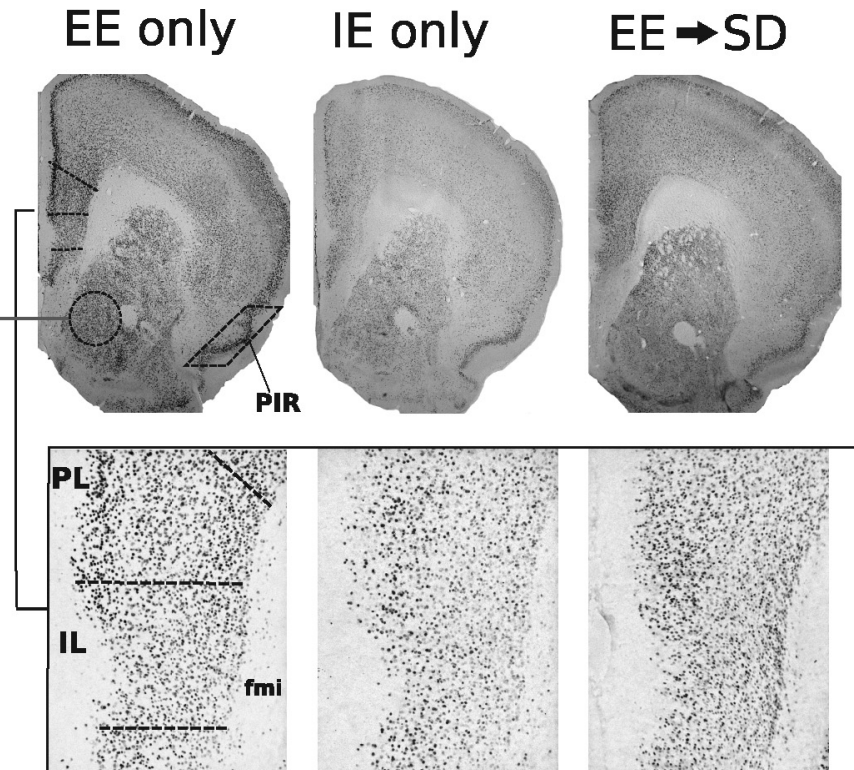

$+8$

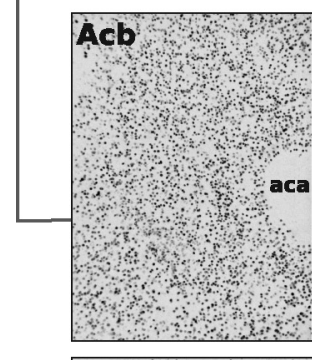

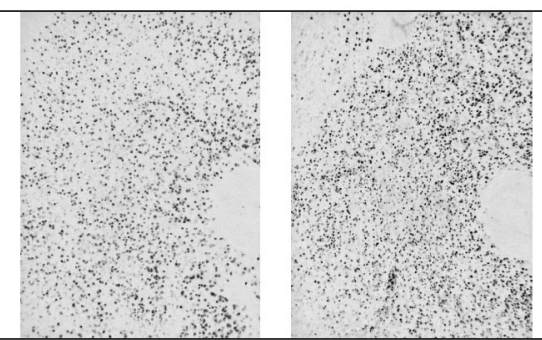
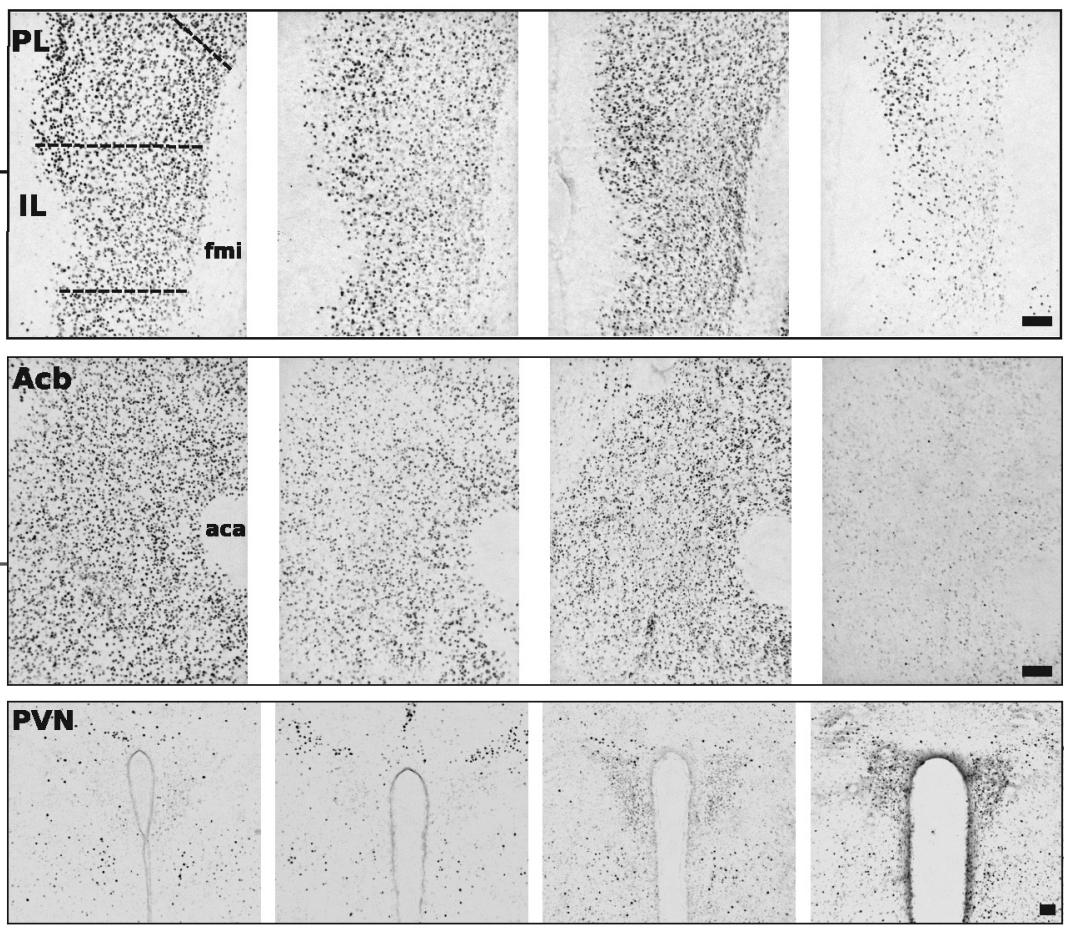

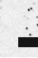

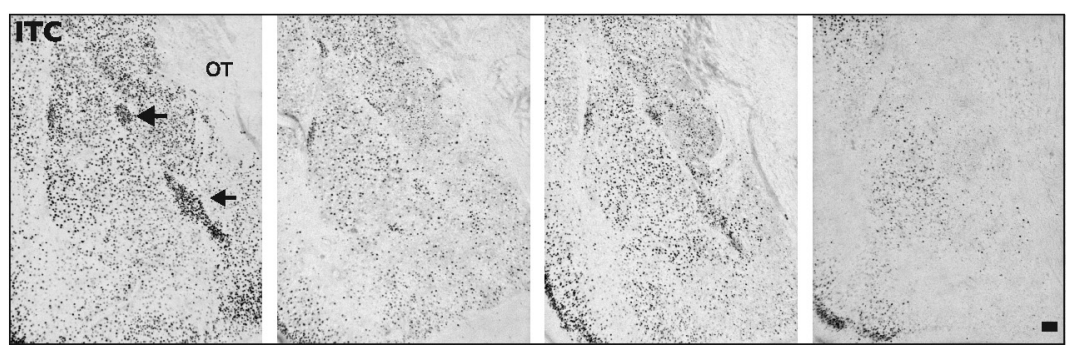

Figure 2. Representative photomicrographs of FosB/ $\triangle F$ osB immunoreactivity within six brain areas showing comparative differences between non-defeated EE or IE-only home-cage mice and defeated mice previously housed in EE or IE. Dashed lines indicate templates within which counts were made. Black arrows point to ITC. aca, Anterior commissure, anterior limb; fmi, forceps minor corpus callosum; 0T, optic tract. Scale bars: 400 and $100 \mu \mathrm{m}$ for low- and high-magnification photographs, respectively.

ing. The last experiment examined whether alterations in behavior and neuronal activity patterns driven by IL-cortex lesions were area specific. The experimental timeline is shown in Figure 10a. Mice received ibotenic acid or vehicle sham infusions either before or after a $21 \mathrm{~d}$ exposure to EE housing. Infusions were directed at either the cingulate (CG) or prelimbic (PL) cortices. Mice were then exposed to $14 \mathrm{~d}$ of social conflict housing, after which they were behaviorally phenotyped (see Fig. 10) or examined histologically for patterns of neuronal activation (see Figs. 11, 12).

\section{Housing conditions}

Impoverished housing. IE consisted of a $14.0 \times$ $35.5 \times 13.0 \mathrm{~cm}$ polycarbonate cage (Tecniplast) with wood chip bedding. To avoid any novel sensory stimulation, bedding was partially changed every $21 \mathrm{~d}$.

Standard housing. SE used a similar cage type as the impoverished housing $(14.0 \times 35.5 \times$ $13.0 \mathrm{~cm}$ ). In addition to standard bedding, a nestlet square and cardboard tube were provided in each cage. Cage bedding was replaced once every $7 \mathrm{~d}$.

Enriched housing. EE consisted of a $24.5 \times$ $40.5 \times 18.5 \mathrm{~cm}$ polycarbonate cage (Tecniplast) with woodchip bedding, nesting material, running wheels, and numerous polycarbonate and paper tubes of different shapes and sizes (BioServ). To both minimize stress from novel objects and maintain a sanitary environment, polycarbonate tubes and wheels were washed with warm water, dried, and replaced in the originating cage once every $7 \mathrm{~d}$.

Social defeat. Repeated SD was used to induce a depressive-like phenotype in intruder mice during the social conflict induction phase. Aggressor CD-1 male mice were single housed in a large polycarbonate cage $(24.0 \times$ $46.0 \times 15.5 \mathrm{~cm}$; Lab Products) for 2-4 weeks with bedding incompletely refreshed once per week. Experimental C57BL/6 mice were subsequently placed into the resident CD-1 mouse's home cage into which a one-eighth-inch-thick perforated transparent polycarbonate partition had been placed down the middle to separate the pair. The partition allowed olfactory, visual, and auditory communication but prevented tactile contact. Testing commenced after a $2 \mathrm{~d}$ accommodation period. The partition was removed for $5 \mathrm{~min} / \mathrm{d}$ for 14 consecutive days (between 4:00 P.M. and 6:00 P.M.) to allow agonistic encounters between the mice. After each interaction period, the partition was replaced with the aggressor male returned to

behavior? Second, is the IL cortex involved in the acquisition of stress resiliency displayed by mice housed in EE? To address this question, mice received IL infusions before EE housing. Third, does the mnemonic of EE exposure responsible for stress resiliency reside within the IL cortex? To address this question, mice received IL infusions after EE housing.

Experiment 3: role of the infralimbic cortex in the acquisition and expression of stress susceptibility after exposure to standard environmental housing. The experimental paradigm for this experiment shown in Figure $7 a$ was identical to experiment 2, except mice were housed in standard housing. All six treatment groups were either behaviorally phenotyped (see Fig. 7) or processed for histology (see Figs. 8, 9).

Experiment 4: site specificity of prefrontal cortical lesion placement in disrupting acquisition of stress resiliency after enriched environmental hous- his initial compartment. Interaction periods were videotaped under red light and later analyzed by an unbiased observer for aggressive, submissive, and exploratory behaviors. In previous experiments, this procedure consistently yielded a subordinate/submissive phenotype in intruder mice (Schloesser et al., 2010).

\section{Surgery}

Anesthesia was induced by inhalation of 5\% isoflurane (Webster Veterinary Supply) in oxygen and was maintained at 2-2.5\% throughout surgery. Mice were placed in a stereotaxic frame (David Kopf Instruments), and an incision was made along the midline to expose the skull. Using a $2.5 \mu$ l gas-tight Hamilton syringe with an attached 32 gauge flat-tipped needle (model 7762; Hamilton), mice were given bilateral injections of 20 
$\mathrm{nl} /$ site ibotenic acid $(10 \mathrm{mg} / \mathrm{ml})$ (Tocris Cookson) or $20 \mathrm{nl} /$ site saline into IL, PL, or CG region of the PFC. Infusions occurred at a rate of $10 \mathrm{nl} / \mathrm{min}$ using a microsyringe pump (World Precision Instruments). After infusion, the needle was left in situ for 15 min to allow for diffusion. Infusion coordinates were determined from the mouse brain atlas of Franklin and Paxinos (1997). Infusion coordinates for the infralimbic cortex were as follows: anteroposterior (AP), $+1.78 \mathrm{~mm}$ from bregma; mediolateral (ML), $\pm 0.4 \mathrm{~mm}$; and dorsoventral (DV), $-2.6 \mathrm{~mm}$ from dura. Infusion coordinates for the prelimbic cortex were as follows: $\mathrm{AP},+1.78 \mathrm{~mm}$ from bregma; $\mathrm{ML}, \pm 0.5 \mathrm{~mm}$; and DV, $-1.2 \mathrm{~mm}$ from dura. Infusion coordinates for the cingulate cortex were as follows: $\mathrm{AP},+1.05 \mathrm{~mm}$ from bregma; $\mathrm{ML}, \pm 0.5 \mathrm{~mm}$; and DV, $-1.0 \mathrm{~mm}$ from dura. After surgery, general health was monitored. Mice were returned to testing $24 \mathrm{~h}$ after surgery.

\section{Behavioral procedures}

Light/dark box test. The light/dark box test was conducted using a Plexiglas box $(50 \times 25 \mathrm{~cm}$ with $30 \mathrm{~cm}$ walls) consisting of a dark (onethird of the box) and a transparent (two-thirds of the box) compartment that was illuminated to $\sim 40$ lux. An open door divided the compartments. Each mouse was placed in the light compartment and allowed to freely move within the compartments for $10 \mathrm{~min}$. The time spent in the dark compartment was measured as an indicator of anxiety-like behavior.

Elevated zero maze test. The elevated zero maze, a model of anxiety-like behavior in rodents, is a modification of the elevated plus maze that addresses the issues concerning the interpretation of time spent in the center square inherent to the elevated plus maze while allowing the animal to have uninterrupted exploration during behavioral testing. The elevated zero maze consists of a white plastic annular platform $5 \mathrm{~cm}$ wide, $54 \mathrm{~cm}$ in diameter, elevated $65 \mathrm{~cm}$ above the ground and divided into four equal quadrants: two open and two closed. The two open quadrants are opposite each other and are surrounded by a $1 \mathrm{~cm}$ lip. The two closed quadrants are enclosed by walls $(16 \mathrm{~cm}$ high) on both the inner and outer edges of the platform. Testing was conducted in a dimly lit room with a constant illumination on the open arms of the maze. At the start of the 6 min testing session, each mouse was placed on the same open arm facing the center of the maze, and the last 5 min were analyzed for time spent in the closed arms. The maze was cleaned with 5\% ethanol and dried after each testing session.

Tail-suspension test. Mice were individually suspended for $6 \min 60 \mathrm{~cm}$ above a bench top from a piece of lab tape $15 \mathrm{~cm}$ long wrapped around the end of their tails. Sessions were videotaped, and the last $5 \mathrm{~min}$ were analyzed using automated behavioral tracking software (Tail Suspension Scan; CleverSystems). The software reliably scores and detects the difference between active struggling mobility, passive swinging mobility, and immobility. Immobility is defined as no movement of the hindlimbs.

Forced-swim test. Mice were placed for $6 \mathrm{~min}$ in a transparent acrylic cylindrical tank (30 cm in height and $10.2 \mathrm{~cm}$ in diameter) filled to a depth of $20 \mathrm{~cm}$ with water $\left(29-30^{\circ} \mathrm{C}\right)$. The mice were unable to escape or rest by touching the bottom of the tank. This session was videotaped, and the last 5 min were analyzed using automated behavioral tracking software (Forced Swim Scan; CleverSystems). The software reliably scores and detects the difference between active struggling mobility and passive floating.

Dominant interaction test. Mice were placed into an open field containing two upside-down wire mesh pencil cups that served as both novel objects and container for the aggressor CD-1 mouse that the experimental mouse had been exposed to during social conflict conditions. Mice were placed in the middle of the open field and allowed to explore for 30 min. Sessions were videotaped and later analyzed using automated behavioral tracking software (TopScan/ObjectScan; CleverSystems). The software reliably scores the frequency and duration of sniffing on either object or mouse through identification of the animal's shape, including nose, body, and tail. Dominant interaction ratios were calculated using the interaction quotient (interaction duration on mouse/interaction duration on empty cup).

\section{Histological investigation}

Mice were deeply anesthetized with Chloropent intraperitoneally and perfused transcardially with $25 \mathrm{ml}$ of $0.9 \%$ saline, followed by $45 \mathrm{ml}$ of ice-cold $4 \%$ paraformaldehyde (PFA) containing 0.1 m phosphate buffer, $\mathrm{pH}$ 7.4. After perfusion, brains were removed immediately and postfixed for $24 \mathrm{~h}$ in $4 \% \mathrm{PFA}$ at $4^{\circ} \mathrm{C}$ and then submerged in $25 \%$ sucrose at $4^{\circ} \mathrm{C}$ for $48 \mathrm{~h}$ before sectioning. Frozen brains were sectioned at $30 \mu \mathrm{m}$ on a sliding microtome. FosB $/ \Delta$ FosB protein was visualized using a standard avidin-biotin-horseradish peroxidase immunohistochemical method. Free-floating sections were washed in PBS, treated with $0.9 \% \mathrm{H}_{2} \mathrm{O}_{2}$ to reduce endogenous peroxidase, blocked with $4 \%$ normal goat serum, and incubated with primary antibody (FosB, 1:1000; sc-48; Santa Cruz Biotechnology) overnight, followed by application of a secondary biotinylated anti-rabbit IgG at 1:500 (Vector Laboratories) and avidin-biotinperoxidase complex. Color was developed using a nickel-enhanced DAB peroxidase substrate (Vector Laboratories).

Areas of interest were counted for FosB-positive cells by NIH Image as described previously (Stone et al., 2006, 2007). The PL and IL regions of the prefrontal cortex were counted for FosB-positive nuclei bilaterally in 
Table 1. $F$ values obtained from the two-way ANOVAs for FosB $/ \Delta F$ osB expression in each brain area for experiments $1-4$

\begin{tabular}{|c|c|c|c|c|c|c|c|c|c|c|c|c|}
\hline \multirow[b]{2}{*}{$\begin{array}{l}\text { Brain } \\
\text { area }\end{array}$} & \multicolumn{3}{|c|}{$\begin{array}{l}\text { Experiment 1: effect of previous } \\
\text { housing on FosB expression } \\
\text { during SD }\end{array}$} & \multicolumn{3}{|c|}{$\begin{array}{l}\text { Experiment 2: effect of IL lesion } \\
\text { and enriched housing on FosB } \\
\text { expression during SD }\end{array}$} & \multicolumn{3}{|c|}{$\begin{array}{l}\text { Experiment 3: effect of IL lesion } \\
\text { and non-enriched housing on } \\
\text { FosB expression during SD }\end{array}$} & \multicolumn{3}{|c|}{$\begin{array}{l}\text { Experiment 4: effect of } \\
\text { ectopic lesions on FosB } \\
\text { expression during SD }\end{array}$} \\
\hline & $\begin{array}{l}\text { Housing }(\mathrm{H}) \\
\operatorname{ANOVAF}_{(2,36)} p\end{array}$ & $\begin{array}{l}\text { Defeat stress }(S) \\
\text { ANOVA } F_{(1,36)}, p\end{array}$ & $\begin{array}{l}\text { Interaction }(\mathrm{H} \times \mathrm{S}) \\
\text { ANOVAF }_{(2,36)}, p\end{array}$ & $\begin{array}{l}\text { IL infusion (L) } \\
\text { ANOVA }_{(1,30)}, p\end{array}$ & $\begin{array}{l}\text { Housing }(\mathrm{H}) \\
\text { ANOVAF }_{(2,30)}, p\end{array}$ & $\begin{array}{l}\text { Interaction }(\mathrm{L} \times \mathrm{H}) \\
\text { ANOVAF }_{(2,30)}, p\end{array}$ & $\begin{array}{l}\text { IL infusion (L) } \\
\text { ANOVAF }_{(1,30)}, p\end{array}$ & $\begin{array}{l}\text { Housing }(\mathrm{H}) \\
\operatorname{ANOVAF}_{(2,30)}, p\end{array}$ & $\begin{array}{l}\text { Interaction }(\mathrm{L} \times \mathrm{H}) \\
\text { ANOVA } F_{(2,30), p}\end{array}$ & $\begin{array}{l}\text { Infusion }(L) \\
\text { ANOVA } F_{(2,30)} p\end{array}$ & $\begin{array}{l}\text { Time of infusion (T) } \\
\text { ANOVA } F_{(1,30)}, p\end{array}$ & $\begin{array}{l}\text { Interaction }(\mathrm{L} \times \mathrm{T}) \\
\text { ANOVA } F_{(2,30)}, p\end{array}$ \\
\hline PL & $27.2, p<0.0001$ & $15.16, p<0.001$ & & $9.62, p<0.004$ & $4.24, p<0.05$ & & & $7.64, p<0.002$ & & $15.18, p<0.001$ & & \\
\hline IL & $65.65, p<0.0001$ & $32.75, p<0.0001$ & $5.23, p<0.05$ & $145.2, p<0.0001$ & & & $48.32, p<0.0001$ & $5.28, p<0.01$ & $6.24, p<0.005$ & & & \\
\hline Acb & $100.1, p<0.0001$ & $103.17, p<0.0001$ & & $28.14, p<0.002$ & $18.37, p<0.0001$ & $7.34, p<0.005$ & & $40.95, p<0.0001$ & & & & \\
\hline CG & $34.81, p<0.0001$ & $10.13, p<0.01$ & $4.97, p<0.05$ & $4.96, p<0.05$ & $41.52, p<0.0001$ & $4.33, p<0.02$ & & $17.23, p<0.0001$ & & $30.92, p<0.001$ & & \\
\hline PIR & $39.91, p<0.0001$ & $23.91, p<0.0001$ & & & $9.95, p<0.01$ & & & & & & & \\
\hline PVN & $13.31, p<0.0001$ & $48.76, p<0.0001$ & $9.114, p<0.001$ & $8.00, p<0.009$ & $10.89, p<0.0031$ & $12.69, p<0.0001$ & & $18.37, p<0.0001$ & & & & \\
\hline ITC & $19.947, p<0.0005$ & $7.826, p<0.01$ & & $17.67, p<0.002$ & $9.719, p<0.0006$ & $5.17, p<0.001$ & & $15.03, p<0.001$ & & & $4.182, p<0.03$ & \\
\hline
\end{tabular}

In experiment 1, the two-way ANOVA examined the interaction between home-cage housing (enriched vs standard vs impoverished) and social defeat exposure (SD exposure vs home-cage housing) on FosB/ $\triangle$ FosB expression in the listed areas. The two-way ANOVA for experiment 2 examined the interaction between IL infusion (ibotenic acid vs vehicle) and housing treatment (ILinf $\rightarrow E E$, ILinf $\rightarrow E E \rightarrow S D$, and EE $\rightarrow$ ILinf $\rightarrow S D$ ) on FosB/ $\Delta$ FosB expression in the listed areas. The two-way ANOVA for experiment 3 examined the interaction between IL infusion (ibotenic acid vs vehicle) and housing treatment (ILinf $\rightarrow$ SE, ILinf $\rightarrow$ SE $\rightarrow$ SD, and SE $\rightarrow$ ILinf $\rightarrow$ SD) on FosB/ $\Delta$ FosB expression in the listed areas. In experiment 4, the two-way ANOVA examined the interaction between $\mathrm{CG} / \mathrm{PL}$ infusions (ibotenic acid vs vehicle) and infusion timing (before vs after EE) on FosB/ $\Delta$ FosB expression in the listed areas. Only statistically significant effects and interactions are included. Nonsignificant analyses have been left blank.

three to four sections closest to $+1.70 \mathrm{~mm}$ from bregma. The CG and piriform (PIR) cortices were counted for FosB-positive nuclei bilaterally in the three to four sections closest to $0.98 \mathrm{~mm}$ from bregma. The nucleus accumbens (Acb), including both the core and shell, was counted in the sections closest to $+1.34 \mathrm{~mm}$ from bregma. Because of difficulty in demarcating the shell and core, it was chosen to count the two combined. The hypothalamic paraventricular nucleus (PVN) was outlined and counted in sections between -0.70 and $-0.94 \mathrm{~mm}$ from bregma. Intercalated cell islands (ITC) of the amygdala, positioned between the basolateral amygdala complex (BLA) and the central amygdala nucleus and intercalated within the medial portion of the external capsule surrounding the BLA, were counted in sections between -1.22 and -1.94 from bregma.

For counting of FosB immunostained nuclei, NIH Image J was set to accept black areas sized between 10 and 100 pixels at a magnification of $100 \times$. The grayscale .tiff image was background-flattened using the rolling-ball feature. The threshold function was used to make the field binary, and counts of labeled cell nuclei (thresholded to black) were made from the binary image. These parameters produced a close agreement between manual and computer-counted fos-positive nuclei in the present sections. A blinded observer made counts for all sections. Representative examples are shown in Figures 3 and 8.

Sections containing the CG, PL, and IL cortices were Nissl stained and microscopically examined with bright-field illumination, and lesions were identified by the characteristic gliosis seen after long-term excitotoxic destruction of neurons. Lesions were traced onto schematic diagrams adapted from the atlas of Franklin and Paxinos (1997) for analysis of placement and extent. Schematic drawings depicting the lesion boundaries in groups receiving lesions before or after EE housing are shown in Figure 13.

\section{Statistical analysis}

Data for all experiments were analyzed using parametric statistics with Student's $t$ test, ANOVA, or multiple-factors ANOVA, as appropriate. ANOVA analysis was followed by post hoc tests or planned comparisons as projected from the design of each experiment.

\section{Results}

We investigated occurrences of stress resiliency to social defeat exposure in mice previously housed in enriched environments. The experimental paradigm is shown in Figure $1 a$. We first compared baseline expressions of anxiety and depressive-like behaviors in mice housed in EE, SE, or IE only (HC conditions in Fig. 1). We then exposed a fresh cohort of EE-, SE-, or IE-housed mice to social defeat stress and examined the influence of previous differential housing on the occurrence of emotional disturbances induced by psychosocial stress (SD conditions in Fig. 1).

Previous exposure to environmental enrichment insulates mice from the deleterious effects of social defeat stress In non-defeated HC control mice, differential environmental housing conditions produced no significant behavioral effect
(Fig. $1 b-e$ ). In comparison, SD significantly increased maladaptive behaviors, but these effects were dependent on previous environmental housing conditions. Mice subjected to $14 \mathrm{~d}$ of SD stress became subordinate and displayed maladaptive, depressive-like behaviors. However, if the social conflict paradigm had been preceded by a $21 \mathrm{~d}$ period of environmental enrichment, in which animals exercised on running wheels and encountered rich multimodal sensory stimulation (EE) instead of isolated (IE) and standard housing (SE), then the maladaptive behaviors after SD were prevented, suggesting that EE produces resiliency to $\mathrm{SD}$. In the elevated zero maze (Fig. $1 b$ ), we observed a significant effect of SD $\left(F_{(1,42)}=24,01 ; p<0.001\right)$; mice exposed to defeat stress showed a significant preference for the covered portions of the elevated zero maze compared with nondefeated control groups. There was no interaction effect of previous housing. In contrast, an interaction effect was observed in all of the remaining tests. In the light/dark test for anxiety (Fig. 1c), mice were placed into the dark compartment, and the amount of time spent in the dark compartment was assessed. Defeated mice previously housed in SE or IE showed a stronger preference for the dark chamber and spent significantly more time in the dark compared with all other groups. The anxiogenic effect of SD was ameliorated in EE-housed mice, which showed a preference for the dark chamber similar to non-defeated controls as indicated by a main effect of social defeat $\left(F_{(1,42)}=22.11 ; p<\right.$ $0.0001)$, a main effect of housing $\left(F_{(1,42)}=3.24 ; p<0.05\right)$, and a significant interaction $\left(F_{(2,42)}=3.77 ; p<0.05\right)$.

We used tail-suspension and forced-swim tests to assess depressive-like behaviors. In the tail-suspension test (Fig. 1d), we observed a significant effect of SD $\left(F_{(1,42)}=54.85 ; p<0.0001\right)$, a main effect of housing $\left(F_{(1,42)}=3.89 ; p<0.05\right)$, and a significant interaction $\left(F_{(1,28)}=3.91 ; p<0.05\right)$. Defeated mice previously exposed to SE or IE housing spent significantly more time immobile compared with defeated mice previously housed in EE and non-defeated controls. A similar behavioral pattern was observed in the forced-swim test (Fig. 1e); time spent immobile was significantly increased in defeated mice previously housed in SE or IE compared with defeated mice previously housed in EE and with non-defeated control animals as indicated by a main effect of social defeat $\left(F_{(1,42)}=34.36 ; p<0.001\right)$, a main effect of housing $\left(F_{(1,42)}=4.67 ; p<0.05\right)$, and a significant interaction $\left(F_{(1,42)}=\right.$ $6.34 ; p<0.05)$. Such an increase in swimming in the $\mathrm{EE} \rightarrow \mathrm{SD}$ compared with $\mathrm{SE} \rightarrow \mathrm{SD}$ or $\mathrm{IE} \rightarrow \mathrm{SD}$ mice represents a longlasting antidepressant-like effect of enriched housing.

Last, we last assessed social interactions with the dominant male mouse versus a neutral object. The expression of avoidance behaviors in response to social defeat stress was affected by envi- 
ronmental housing conditions before social defeat exposure (Fig. 1f,g). Mice housed in EE before receiving $14 \mathrm{~d}$ of social defeat had a significantly increased interaction ratio $\left(F_{(2,42)}=14.47 ; p<\right.$ $0.0001)$ and spent significantly more time (EE, $227.1 \pm 25.49$ vs SE, $103.6 \pm 2.14$ and IE, $119.6 \pm 14.64)\left(F_{(2,42)}=36.73 ; p<\right.$ $0.0001)$ investigating the aggressor mouse compared with SE- or IE-housed mice.

Environmental enrichment increases FosB/DFosB immunohistochemical expression in brain areas associated with positively motivated behaviors and protects against the suppression caused by social defeat

Although stress-related disorders are etiologically diverse, abnormal activity in brain regions subserving motivated activities, reward, attention, and active coping responses are commonly observed in patients suffering from major depressive disorder and PTSD. Regions found to show abnormal activity include the prefrontal, cingulate, and rostral temporal cortices, and subcortical structures, including the amygdala and ventral striatum (Price and Drevets, 2010). We examined induced FosB $/ \Delta$ FosB neuronal immunostaining in rodent brain structures that have homology with structures affected in depressed patients. Compared with the transient presence of other neuronal activity markers, FosB $/ \Delta$ FosB expression is sustained during chronic stimulation and therefore is useful for identifying the functional neuroanatomical correlates of stress resiliency displayed by defeated mice previously housed in EE. FosB $/ \Delta$ FosB expression was examined after EE-only, SE-only, or IEonly housing (differential home-cage environments) and after $\mathrm{EE} \rightarrow \mathrm{SD}, \mathrm{SE} \rightarrow \mathrm{SD}$, or $\mathrm{IE} \rightarrow \mathrm{SD}$ to, first, compare differences in neuronal activation after differential housing (EE vs SE vs IE) and, second, demonstrate that previous environmental housing modulates the response of neuronal pathways to chronic social defeat stress. As shown in the photomicrographs in Figure 2 and the cell-count analysis in Figure 3, differential housing and SD stress were sources of major alterations in cellular activity in all examined areas ( $F$ scores shown in Table 1, Experiment 1). In non-defeated home-cage control groups, exposure to enriched housing, in contrast to standard and impoverished housing, greatly increased numbers of FosB-stained cells in limbic cortical areas processing emotion, i.e., the PL, IL, PIR, CG, and ITC, and in striatal areas processing reward, i.e., the Acb (Fig. 3a-f). The expression of FosB $/ \Delta$ FosB-positive cells during social defeat stress was strongly affected by

\section{a Effect of IL Lesion (ILinf $\rightarrow$ EE)}

IL Infusion ${ }^{35 d} \quad$ Enrichment (EE)

Acquisition of Resiliency (ILinf $\rightarrow \mathrm{EE} \rightarrow \mathrm{SD}$ )

IL Infusion 21d Enrichment (EE)
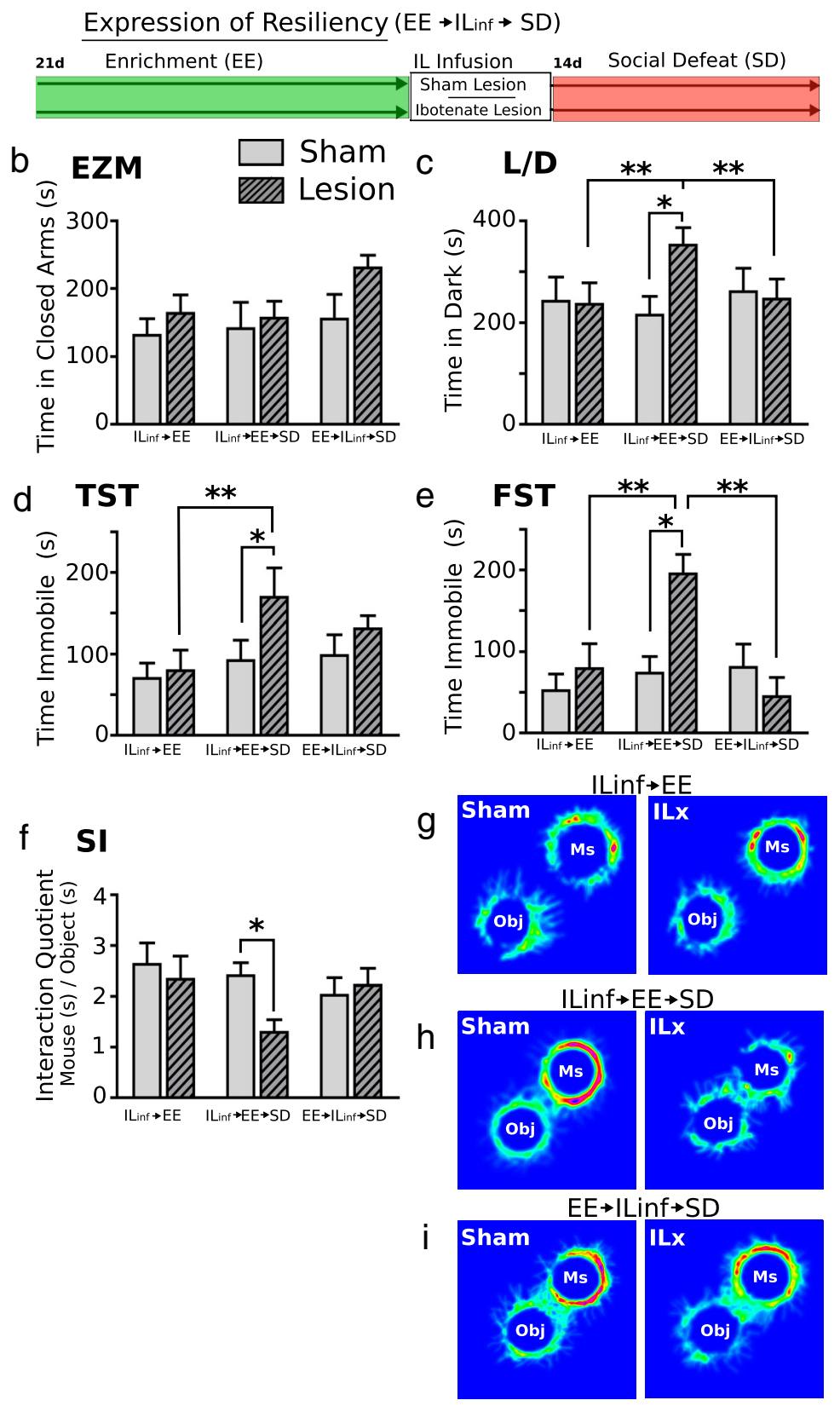

Figure 4. Neurons of the infralimbic cortex are involved in the acquisition, but not the expression, of stress resiliency displayed by mice previously housed in EE. The diagram depicting experimental groups and second study design is shown in $\boldsymbol{a}$. Resiliency to SD was measured by behavioral responses to the elevated zero maze (EZM, $\boldsymbol{b})$, light/dark box (L/D, $\boldsymbol{c})$, tail-suspension test (TST, $\boldsymbol{d})$, forced-swim test (FST, $\boldsymbol{e}$ ), and social interaction task (SI, $\boldsymbol{f}-\boldsymbol{i})$. Mice given IL lesions before EE showed a strong anxiety response to SD and spent significantly more time in the dark chamber of the light/dark box (c) compared with all other treatment groups. IL lesions before EE significantly increased depressive-like behaviors after SD; mice spent significantly more time immobile in the tail-suspension test $(\boldsymbol{d})$ and forced-swim test $(\boldsymbol{e})$ and spent significantly less time with the aggressor mice in the social interaction task $(\boldsymbol{f}, \boldsymbol{g})$ compared with all other treatment groups. IL lesions had no effect on behavior in non-defeated groups. In defeated groups, lesions made after EE had no effect on behavioral response to SD. ILinf, IL Infusion; ILx, IL lesion; Ms, mouse; Obj, object. Results are expressed as mean \pm SEM ( $n=8$ per group). Two-way ANOVA followed by Bonferroni's posthoc test. Bonferroni's test: ${ }^{*} p<0.05 ;{ }^{* *} p<0.01$. 


\section{$I L x \rightarrow E E \quad I L x \rightarrow E E \rightarrow S D \quad E E \rightarrow I L x \rightarrow S D$}
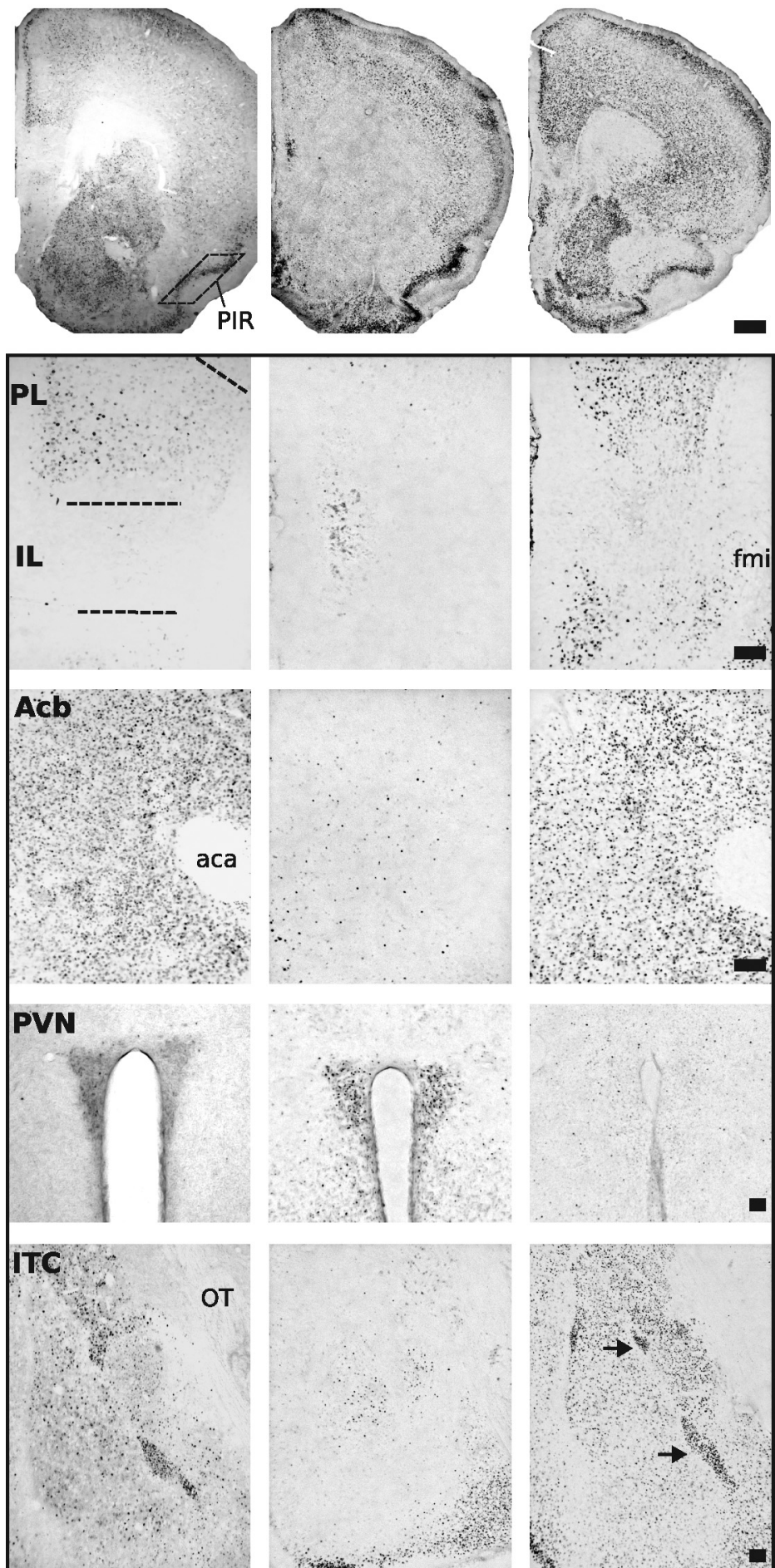

Figure 5. Representative photomicrographs of $\mathrm{Fos} B / \Delta \mathrm{Fos} B$ immunoreactivity within six brain areas that show comparative differences between non-defeated mice that received IL lesions before enrichment (ILX $\rightarrow \mathrm{EE})$ and defeated mice that received IL lesions before (ILX $\rightarrow \mathrm{EE} \rightarrow \mathrm{SD}$ ) or after ( $\mathrm{EE} \rightarrow \mathrm{ILx} \rightarrow \mathrm{SD}$ ) enriched housing. Lesions of IL cortex before EE nearly abolished Fos $B / \Delta$ Fos $B$ immunostaining after $S D$ in prefrontal cortical regions and facilitated Fos $B / \Delta F$ Fos $B$ immunostaining in the PVN. In contrast, mice that received IL lesions after EE then exposed to SD (EE $\rightarrow I L x \rightarrow S D$ ) show FosB/ $\Delta$ Fos B immunostaining in PFC and PVN similar to non-defeated lesion control groups (IL $\rightarrow$ EE). Dashed lines indicate templates within which counts were made. Black arrows point to ITC. For abbreviations, see Figure 2 legend. Scale bars: 400 and 100 $\mu \mathrm{m}$ for low- and high-magnification photographs, respectively. previous environmental housing conditions. Mice housed in standard or impoverished housing before $\mathrm{SD}(\mathrm{SE} \rightarrow \mathrm{SD}$ and $\mathrm{IE} \rightarrow \mathrm{SD}$, respectively) showed significant declines in numbers of FosB $/ \Delta$ FosB immunostained neurons in the PL, IL, PIR, CG, ITC, and Acb compared with non-defeated control groups (SE-HC and IE-HC) and $\mathrm{EE} \rightarrow \mathrm{SD}$ groups. Strikingly, social defeat had no effect on the expression of FosB/ $\Delta \mathrm{FosB}$ in the IL, PIR, CG, and ITC of mice previously housed in EE. Within these areas, FosB $/ \Delta$ FosB was expressed during SD exposure at levels similar to non-defeated EE-HC control groups. In the Acb and PL, however, FosB $/ \Delta$ FosB expression was significantly attenuated during social defeat; $\mathrm{EE} \rightarrow \mathrm{SD}$ contrasted with non-defeated EE-HC controls. However, even at these attenuated levels, FosB/ $\Delta$ FosB expression was significantly and robustly higher compared with $\mathrm{SE} \rightarrow \mathrm{SD}$ and $\mathrm{IE} \rightarrow \mathrm{SD}$ mice.

\section{Environmental enrichment suppresses $S D$-induced FosB $/ \Delta$ FosB expression in the PVN}

In contrast to the inhibitory effects of SD on FosB $/ \Delta$ FosB expression in the prefrontal cortex and Acb, SD significantly increased FosB $/ \Delta$ FosB in the PVN of both SE- and IE-housed mice (Fig. $3 g$ ), indicating that SD differentially and singularly activates the major effector of the central stress response via the HPA axis. Strikingly, and in the opposite direction from its effects on the limbic cortical areas, EE before defeat exposure suppressed the defeat-induced PVN response; $\mathrm{EE} \rightarrow \mathrm{SD}$ mice showed no significant increase in FosB $/ \Delta$ FosB staining and instead showed levels that were comparable with nondefeated control groups.

\section{Mice previously housed in SE or IE show similar levels of affective behaviors and patterns of neuronal activity after social defeat}

The behavioral response (Fig. 1) and FosB/ $\Delta$ FosB expression patterns (Fig. 3 ) after social defeat were the same in SE- or IEhoused mice. The lack of difference suggests that enrichment before SD produces a positive outcome as opposed to the alternative possibility that impoverishment before SD produces a negative outcome.

\section{Neurons of the infralimbic cortex are involved in the acquisition, but not the expression, of stress resiliency displayed by mice previously housed in EE}

In the first experiment, we showed that repeated defeat stress induced reliable in- 
dices of depressive-like and anxiety-like behaviors, and mice housed in EE before exposure to SD exhibited resilience to its deleterious effects. Notably, the expression of behavioral resilience was concordant with FosB expression in the prefrontal and limbic areas processing emotion. One of the responsive limbic cortical areas was the IL area of the mPFC. Also activated by $\mathrm{EE}$ were areas known to receive anatomical connections from the IL cortex and thought to be responsive to its activity: the Acb and ITC (Sesack et al., 1989; Mcdonald et al., 1996; Vertes, 2004).

The second experiment was designed to test the role of IL cortex in the stressprotective effects afforded by EE (Fig. 4). Ibotenate IL lesions were made either before EE, to assess the role of the IL cortex in acquisition of the systemic neurobiological effects of EE, or after EE, to assess the possibility that the IL cortex is needed for the expression of the protective effects of EE.

Furthermore, previous behavioral studies investigating the effects of PFC lesions on anxiety-related behavior have yielded an inconsistent body of findings (Jinks and McGregor, 1997; Lacroix et al., 1998). Therefore, to control for differences in lesion methodology and to examine the effect of lesion on behavior in nondefeated mice, a third cohort received IL ibotenic acid lesions before EE housing, and behavior was examined at the end of EE housing.

The experimental design is shown in Figure $4 a$. We used elevated zero maze and light/dark test to assess anxiety, and we used tail suspension, forced swim, and social interaction to measure behavioral despair and depressive-like behaviors. No significant effect of lesion or housing was detected in the elevated zero maze (Fig. 4b). In the light/dark test (Fig. 4c), a two-way ANOVA detected a significant effect of infusion $\left(F_{(1,42)}=4.34 ; p<0.05\right)$ and a significant interaction effect between lesion and housing treatment $\left(F_{(2,42)}=\right.$ $4.68 ; p<0.05)$.

In mice receiving IL lesions before EE, social defeat had significant anxiogenic effects compared with sham lesioned mice; lesioned mice spent significantly more time in the dark compartment of the light dark box (Bonferroni's post hoc test, $p<0.0 .5$ ). In contrast, mice receiving lesions after EE showed no significant change in anxiety-like behavior after social defeat compared with sham controls. In non-defeated groups, lesions had no effect on anxiety behavior. Interestingly, mice administered lesions after EE housing showed levels of anxiety similar to non-defeated groups and to sham-lesioned defeated groups, suggesting that resiliency to defeat stress remained intact in these mice.

In the tail-suspension test (Fig. $4 d$ ), two-way ANOVA detected a significant effect of infusion $\left(F_{(1,42)}=4.16 ; p<0.05\right)$. In the forced-swim test (Fig. 4e), a two-way ANOVA of immobility time revealed significant effect of housing treatment $\left(F_{(2,42)}=\right.$ $5.32 ; p<0.01)$ and a strong interaction effect $\left(F_{(2,42)}=5.17 ; p<\right.$ $0.01)$. Immobility in the forced-swim test was significantly
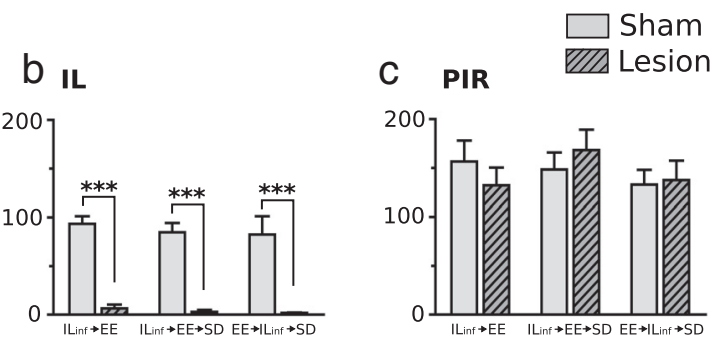

e $\mathbf{A c b}$
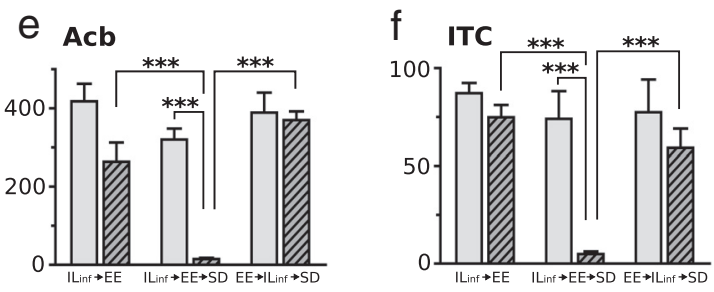

Figure 6. Lesions of the IL cortex before (ILinf $\rightarrow \mathrm{EE} \rightarrow \mathrm{SD}$ ), but not after ( $\mathrm{EE} \rightarrow \mid \mathrm{Linf} \rightarrow \mathrm{SD}$ ), EE housing alter the pattern of $\mathrm{EE} ; \mathrm{no}$ change was observed in animals that received lesions after EE. Results are expressed as mean $\pm \mathrm{SEM}$ ( $n=6$ per group). Two-way ANOVA followed by Bonferroni's post hoc test. Bonferroni's test: ${ }^{*} p<0.05$; ${ }^{* * *} p<0.001$.

greater in defeated mice receiving IL lesions before EE housing compared with all other groups (Bonferroni's post hoc, $p<0.05$ ). No significant change in immobility time was observed between defeated groups that received sham or ibotenic acid lesions after EE. No significant difference in immobility time was observed between non-defeated IL lesion and sham lesion mice. Thus, in groups exposed to social defeat, lesions of IL cortex before EE prevented the acquisition of stress resiliency. However, IL lesions after EE housing had no effect on behavioral expression of resiliency. Finally, in non-defeated mice, IL lesion had no observable effect on affective behaviors.

We showed previously that the avoidance of an aggressor mouse is a maladaptive response coincident with anxiety and depressive-like behaviors, which can be reversed by EE housing (Schloesser et al., 2010). Here we observed a significant interaction $\left(F_{(2,42)}=5.88 ; p<0.05\right)$ between lesion and housing conditions in this test. In mice that received IL lesions before EE, social defeat significantly reduced the dominance interaction quotient compared with mice receiving sham lesions (Bonferroni's post hoc, $p<0.05$ ) (Fig. $4 f-i$ ). However, groups receiving IL lesions after EE showed an interaction quotient similar to sham lesion group. In non-defeated groups, IL lesions had no effect on interaction quotients; these groups displayed an interaction quotient similar to defeated mice that received lesions after EE. Thus, if lesions were administered before EE, then social defeat would 
a

Effect of IL Lesion (ILinf $\rightarrow$ SE)
IL Infusion 35d $\quad$ Standard Housing (SE)
$\begin{aligned} & \text { Sham Lesion } \\ & \text { Ibotenate Lesion }\end{aligned}$

Acquisition of Resiliency $\quad(\mathrm{ILinf} \rightarrow \mathrm{SE} \rightarrow \mathrm{SD})$

\begin{tabular}{|c|c|c|c|c|}
\hline IL Infusion & 21d & Standard Housing (SE) & 14d & Social Defeat (SD) \\
\hline \begin{tabular}{|l} 
Sham Lesion \\
\end{tabular} & & & & \\
\hline
\end{tabular}

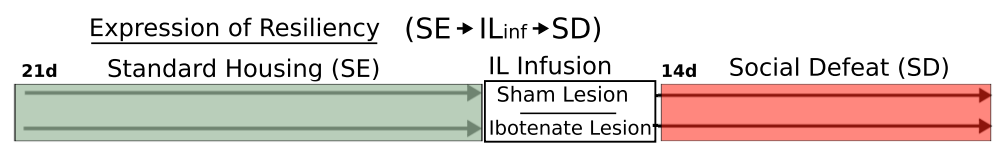

$b$

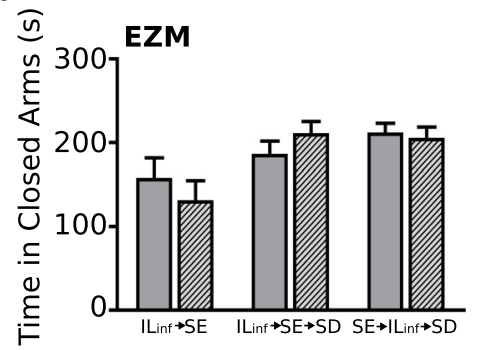

d
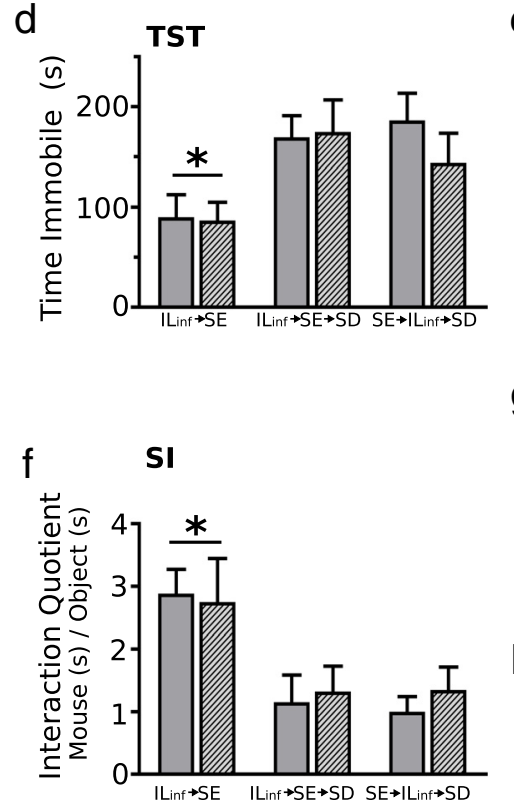

g

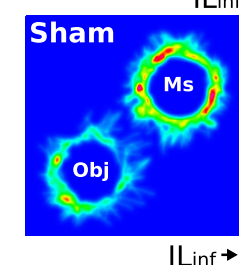

$\mathrm{h}$
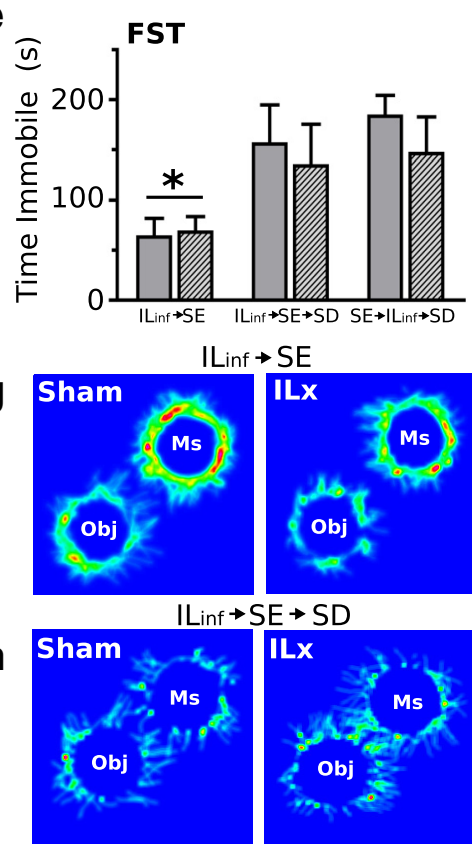

$\mathrm{ILinf} \rightarrow \mathrm{SE}$

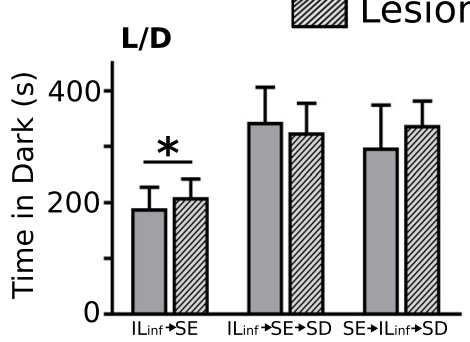
Sham

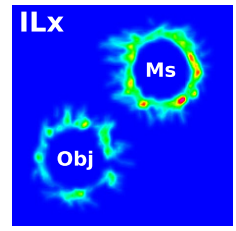

$\mathrm{SE} \rightarrow \mathrm{SD}$

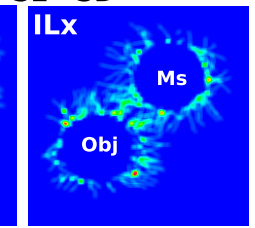

$\mathrm{SE} \rightarrow \mid \mathrm{Linf} \rightarrow \mathrm{SD}$

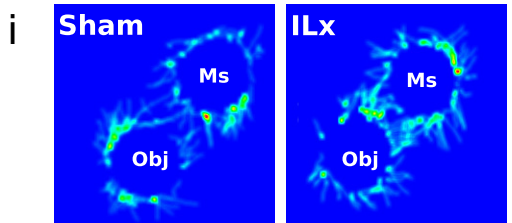

Figure 7. Lesions of the IL cortex have no effect on affective behaviors in defeated mice previously housed in standard environments. The diagram depicting experimental groups and third study design is shown in $\boldsymbol{a}$. Behavioral responses are measured in the elevated zero maze (EZM, $\boldsymbol{b})$, light/dark box (L/D, $\boldsymbol{c})$, tail-suspension test (TST, $\boldsymbol{d})$, forced-swim test (FST, $\boldsymbol{e})$, and social interaction task $(S \mathrm{~S}, \boldsymbol{f}-\boldsymbol{i})$. IL lesions made before or after SE housing had no effect on displays of anxiety or depressive-like behaviors. Groups exposed to SD, regardless of infusion type, showed significant increases in anxiety and spent significantly more time in the dark chamber of the light/darkbox (c) compared with non-defeated groups. Defeated groups spent significantly moretimeimmobile in the tail-suspension test $(\boldsymbol{d})$ and forced-swim test $(\boldsymbol{e})$ and spent significantly less time with the aggressor mice in the significantly increase maladaptive behavior; however, if lesions were administered after EE, then animals continued to show resiliency to social defeat stress.

Lesions of the IL cortex before, but not after, EE housing alter the pattern of Fos $B / \Delta$ FosB expression in response to chronic social defeat stress

Through connections to hypothalamic and other limbic structures, the IL cortex regulates emotional memory formation. To determine the role of the IL cortex in the acquisition and/or expression of stress resiliency displayed by mice housed in $\mathrm{EE}$, we examined SD stress-induced FosB/ $\Delta$ FosB expression in mice that received IL lesions either before or after EE exposure. Photomicrographs of the examined regions are shown in Figure 5. As illustrated in Figure $6 a-g$, four distinct patterns of Fos $\mathrm{B} / \Delta$ FosB immunostaining emerged from examined brain regions in response to infusion type and housing conditions. Falling in the first pattern are areas that remained unresponsive to infusion type or housing, including the PIR. In the second pattern are areas that responded to infusion type under stress exposure but not during home-cage conditions, including PL. Within this area, groups receiving IL lesions either before or after EE showed a significant reduction in FosB/ $\Delta$ FosB expression during SD but no significant change in non-SD groups ( $F$ scores shown in Table 1, Experiment 2). The IL represents the third pattern because this area was the target of ibotenate, and a significant reduction in FosB $/ \Delta$ FosB was detected in all lesion groups. The fourth pattern represents areas that showed a significant interaction between infusion type and housing condition, including the CG, Acb, ITC, and PVN. In these areas, lesions in non-defeated groups had no effect. In defeated groups, FosB expression was significantly altered only if the IL was lesioned before EE. The effect of lesion was temporally specific because no effect of lesion was observed in mice receiving IL lesions after EE housing.

Interestingly, the direction of the FosB response was highly specific to the area or circuit examined. For instance, defeated

social interaction task $(\boldsymbol{f}, \boldsymbol{g})$ compared with non-defeated controls. IL lesions had no effect on behavior in non-defeated groups. In defeated groups, lesions made before or after SE had no effect on behavioral response to SD. ILinf, IL Infusion; ILx, IL lesion; Ms, mouse; 0bj, object. Results are expressed as mean $\pm \operatorname{SEM}$ ( $n=8$ per group). Two-way ANOVA followed by Bonferroni's post hoc test. Bonferroni's test: ${ }^{*} p<0.05$. 
mice receiving ibotenic acid lesions before EE showed an extreme reduction of FosB/ $\Delta$ FosB expression in the Acb, CG, and ITC but a large elevation in PVN staining (Figs. 6, 7). Thus, the ability of EE to suppress $\mathrm{SD}$-induced FosB $/ \Delta$ FosB expression in the PVN is abolished if the IL cortex is lesioned before EE. The abolition was not observed in mice receiving IL lesions after EE housing.

\section{Lesions of the IL cortex have no effect on the display of affective behaviors in defeated mice previously housed in standard environments}

Previous environmental housing conditions strongly influence behavioral reactivity and neuronal activity to subsequent stressors. Whereas EE inoculates mice from the deleterious effects of SD, SE or IE does not. The second experiment showed that behavioral resilience to social defeat, exhibited after EE housing, might be gated by neurons in the IL. To determine whether the effect of lesions were dependent on the type of housing, the third set of experiments examined the effect of IL lesion on stress reactivity in mice housed in standard environments. Similar to the second experiment, and as illustrated in Figure $7 a$, mice were given ibotenate IL lesions or sham lesions either before or after $21 \mathrm{~d}$ exposure to standard housing, after which they were given $14 \mathrm{~d}$ of social defeat stress. Non-defeat control groups were given IL infusions before constant home-cage housing in SE.

As shown in Figure $7 b-i$, IL infusions had no effect on the induction of anxietyand depressive-like behaviors after SD. In both lesion and sham groups, a robust response to SD was detected in the elevated zero maze (Fig. $7 b)\left(F_{(2,42)}=6.41 ; p<\right.$ $0.001)$ light/dark test (Fig. $7 c)\left(F_{(2,42)}=\right.$ 3.59; $p<0.05$ ), tail-suspension test (Fig. $7 d)\left(F_{(2,42)}=5.35 ; p<0.01\right)$, forced-swim test $($ Fig. $7 e)\left(F_{(2,42)}=5.25 ; p<0.01\right)$, and social interaction test (Fig. $7 f-i)\left(F_{(2,42)}=\right.$ 7.96; $p<0.005)$. Compared with nondefeated groups, mice exposed to SD, regardless of infusion treatment, showed significant increases in anxiety and depressive-like behaviors. As expected, IL lesions had no effect on affective behaviors in non-defeated SE-housed mice.
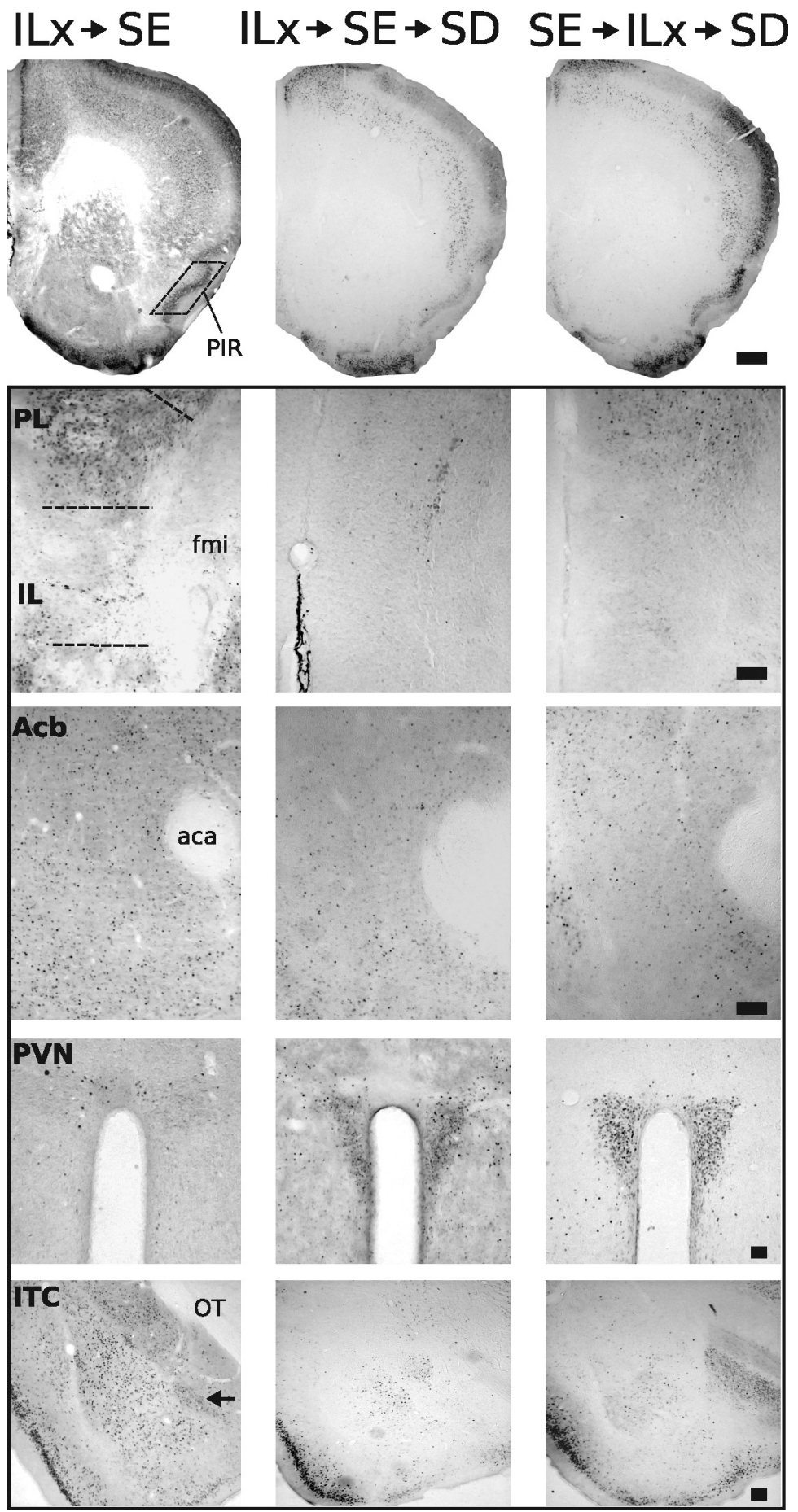

Figure 8. Representative photomicrographs of $\mathrm{Fos} B / \Delta \mathrm{FosB}$ immunoreactivity within six brain areas that show comparative differences between non-defeated mice that received IL lesions before $\mathrm{SE}(\mathrm{ILX} \rightarrow \mathrm{SE})$ and defeated mice that received IL lesions before (ILx $\rightarrow S E \rightarrow S D$ ) or after (SE $\rightarrow I L x \rightarrow S D$ ) standard environmental housing. Groups exposed to SD (ILx $\rightarrow S E \rightarrow S D$ and $\mathrm{SE} \rightarrow \mid \mathrm{Lx} \rightarrow \mathrm{SD}$ ) show diminished FosB $\triangle \triangle$ FosB immunostaining in prefrontal cortical regions and enhanced FosB $\triangle \mathrm{Fos} B$ immunostaining in the PVN compared with non-defeated groups (ILx $\rightarrow$ SE). Dashed lines indicate templates within which counts were made. Black arrows point to ITC. For abbreviations, see Figure 2 legend. Scale bars: 400 and $100 \mu \mathrm{m}$ for low- and highmagnification photographs, respectively.

\section{In SE-housed mice, IL cortex lesions}

have no effect on FosB $/ \Delta$ FosB expression during chronic social defeat

Significant effects of infusion treatment, and housing condition and an interaction between infusion and housing condition on FosB/ $\Delta$ FosB expression were detected only in the IL cortex ( $F$ scores shown in Table 1 , Experiment 3 ). In this area, FosB $/ \Delta$ FosB expression was significantly reduced by lesion and by exposure to SD. In striking contrast to groups housed in EE, no main effect of infusion treatments was detected in any area outside the infusion target (photomicrographs in Fig. 8 and graphs in Fig. $9 a-g$ ). A significant effect of housing treatment was detected in the Acb, ITC, and PVN (F scores shown in Table 1, Experiment 3). Com- 

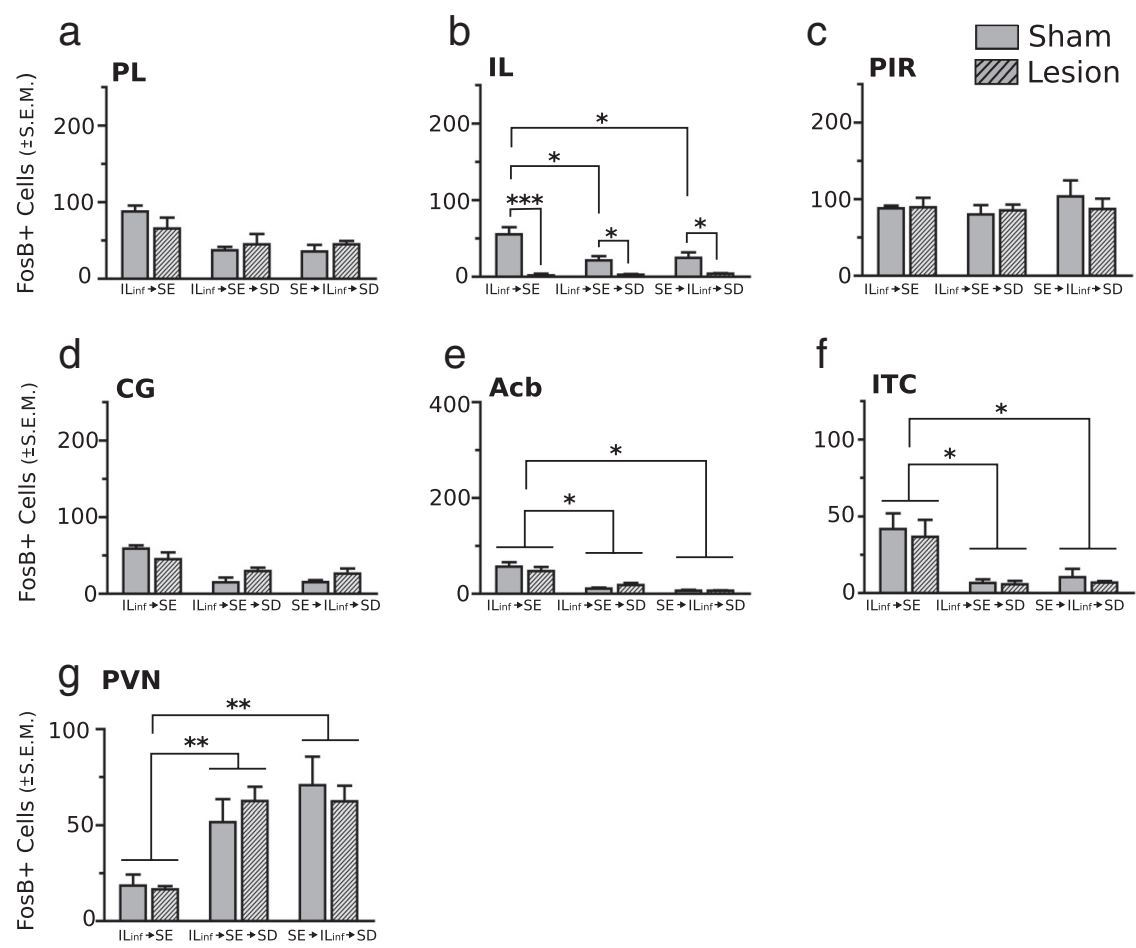

Figure 9. Lesions of the IL cortex have no effect on FosB $/ \Delta$ FosB expression in defeated mice previously housed in standard environments. No significant difference between groups was observed in the PL (a), PIR (c), or CG (d). Groups exposed to SD after SE housing showed a significant reduction in FosB/ $\Delta$ FosB expression in the IL $(\boldsymbol{b}), A c b(\boldsymbol{e})$, and ITC $(\boldsymbol{f})$ compared with non-defeated groups. FosB/ $\Delta$ FosB immunostaining in the PVN $(\boldsymbol{g})$ was significantly enhanced after SD, regardless of infusion treatment. IL, IL infusion. Results are expressed as mean \pm SEM ( $n=6$ per group). Two-way ANOVA followed by Bonferroni's post hoc test. Bonferroni's test: ${ }^{*} p<0.05 ;{ }^{* *} p<0.01 ;{ }^{* * *} p<0.001$.

pared with non-defeated groups, FosB/ $\Delta$ FosB expression was significantly attenuated after SD in the Acb and ITC. In the PVN, groups exposed to $\mathrm{SD}$ showed a robust increase in FosB $/ \Delta$ FosB expression, regardless of infusion treatment. Compared with the data from EE (compare Figs. 6, 9), it is clear that the resilience to $\mathrm{SD}$ requires a previous enriched environment because the mere passage of time in SE does not confer resilience.

\section{Lesions of the dorsomedial PFC have no effect on the acquisition of stress resiliency after enriched environmental housing}

As shown in experiment 2 (Figs. 4-6), lesions of the IL in the ventromedial PFC significantly disrupted the acquisition of resiliency to social defeat, provided that lesions were made before EE housing. A fourth experiment examined whether this effect was specific to the ventromedial PFC. As shown in Figure $10 a$, mice received infusions either before or after $\mathrm{EE}$, and all mice were then exposed to SD. Infusions were directed toward either the PL (Ibotenic Acid-PL) or CG (Ibotenic Acid-CG) cortices. Because of the close proximity of these areas, ibotenic acid showed considerable spread across both regions. Therefore, two statistical analyses were performed; lesions targeting the CG or PL were analyzed either independently as individual groups or binned together. For graphical presentation, individual groups are shown. In sham-lesioned groups, the spread of vehicle infusion could not be determined. Therefore, for statistical analysis and graphical presentation, sham groups for both behavior and FosB analysis were collapsed into a single group.

In a nonbinned analysis (CG and PL treated independently), no significant effect of lesion treatment or housing condition was detected in any of the examined behaviors (Fig. 10b-h). If infusion target areas were binned $(\mathrm{CG}+\mathrm{PL})$, then a significant main effect of infusion was detected in the forced-swim test $\left(F_{(1,40)}=7.18 ; p<0.03\right)$. However, post hoc test comparisons showed no significant differences between groups $(p<0.05)$.

To complement the behavioral data, neuronal activity via FosB/ $\Delta$ FosB expression was examined in a fresh cohort of mice. Photomicrographs of the examined regions are shown in Figure 11, and cellcount analysis is shown in Figure 12. Lesion extents are shown in Figure 13. As illustrated in Figure 12, significant main effects of infusion treatment were detected in regions targeted for infusions $(F$ scores shown in Table 1, Experiment 4). In a nonbinned analysis, no significant effect of infusion type or infusing timing was detected in regions outside infusion target areas. If infusion trials were binned (CG + PL infusions), then significant main effects of infusion type were detected in the $\operatorname{Acb}\left(F_{(1,40)}=4.66 ; p<0.04\right)$ and $\operatorname{ITC}\left(F_{(1,40)}=8.54 ; p<0.01\right)$. Post hoc test comparisons revealed no significant differences for either region.

In summary, a striking parallel profile occurs across all experiments, for both behavior and FosB cell activation, as follows. The FosB expression pattern induced by SD in mice receiving IL lesions before EE (Fig. 6) is similar to that in mice housed in IE before SD (Fig. 3) and is concordant with the maladaptive responses observed after social defeat stress in both of these groups (Figs. 4 and 1, respectively).

\section{Discussion}

The behavioral results show that enriched environmental housing can confer profound psychological resilience to chronic social defeat effects manifested as anxiety-like, depressive-like, and social avoidance behaviors. The FosB/ $\Delta$ FosB immunohistochemical data identified areas of the brain that may mediate this stress resiliency. Mice exposed to enriched environments, in contrast to impoverished or standard housing, showed robust FosB $/ \Delta$ FosB expression in forebrain and limbic areas associated with emotional regulation and reward processing. Interestingly, this EEinduced robust expression pattern was maintained during SD exposure, whereas it was completely abolished in $\mathrm{SE} \rightarrow \mathrm{SD}$ and $\mathrm{IE} \rightarrow \mathrm{SD}$ mice. A parallel but strikingly opposite pattern of activation was found in the hypothalamic PVN, in which increased numbers of FosB-stained neurons were found only in defeated mice previously housed in SE or IE; the defeat-induced increases were prevented by previous EE.

Next, we tested the putative involvement of the ventromedial PFC in mediating resilience by selectively lesioning the IL cortex either before or after EE housing and then exposing the mice to SD. We found that IL lesions made before but not after enriched housing block the stress resiliency afforded by EE, attenuated FosB $/ \Delta$ FosB expression in the Acb and ITC, and increased expression in the PVN. This suggests that reduced or otherwise pathological IL cortical outputs to downstream limbic targets 
could predispose an individual to anxiety disorders in stressful situations, whereas enhanced IL cortical outputs could convey stress resilience. Lesions that did not include the ventromedial PFC were unable to significantly disrupt the acquisition of resiliency.

The dorsal and ventral aspects of the mPFC differentially regulate stress-induced HPA activation (Radley et al., 2006). The current experiments show that lesions of the IL but not PL/CG affect the induction of affective disorders; observations that are not congruent with previously reported findings. Whereas the dorsal PFC, through projections to the dorsomedial hypothalamus and peri-PVN, attenuates HPA response to stress, the IL is implicated in HPA activation (Sesack et al., 1989; Hurley et al., 1991). HPA activation during enrichment may explain this discordance. EE is a eustressor; that is, EE is associated with elevated yet constrained HPA activation, and it renders the HPA axis more adaptive to future distressors as it attenuates emotional reactivity and increases emotional stability (Chapillon et al., 1999; Greenwood and Fleshner, 2008; Sasse et al., 2008). Concordant with these findings, the strong induction of FosB in the PVN of defeated mice was prevented if defeated mice were previously housed in EE. Thus, an inoculation against distressful stimulation was achieved by eustressful stimulation received during $\mathrm{EE}$, consistent with other evidence showing that mild stressors enhance resiliency to future severe stressors (Lyons and Parker, 2007). Future work will show the role played by the HPA axis and corticosterone in the effects of EE and SD on depressive-like and anxiety-like behaviors.

\section{Relationship of experimental conditions and results to human pathology}

Social defeat is an ethologically relevant stress with a high translational value. In humans, this stressor plays a significant role in the onset of a variety of psychopathologies, including depression, anxiety, and PTSD (Kudryavtseva and Avgustinovich, 1998; Bremner, 2004; Huhman, 2006). We and others have shown that, as mice accumulate social defeats, profound and stable behavioral changes reminiscent of depression occur (Kudryavtseva and Avgustinovich, 1998; Huhman, 2006; Schloesser et al., 2010). Animals that show fewer of these behaviors are considered resilient, i.e., more resistant to and adaptable to deleterious effects of stressful situations.

Although a broad range of environmental and genetic factors contribute to resilience, little is known about the underlying biological processes associated with it. Many studies have demonstrated that stress-induced structural changes in the mPFC, including dendritic shortening (Holmes and Wellman, 2009) and decreased cortical volume (Cerqueira et al., 2005; Bessa et al., 2009), are critical to the pathophysiology of depression. Treatments that reverse these
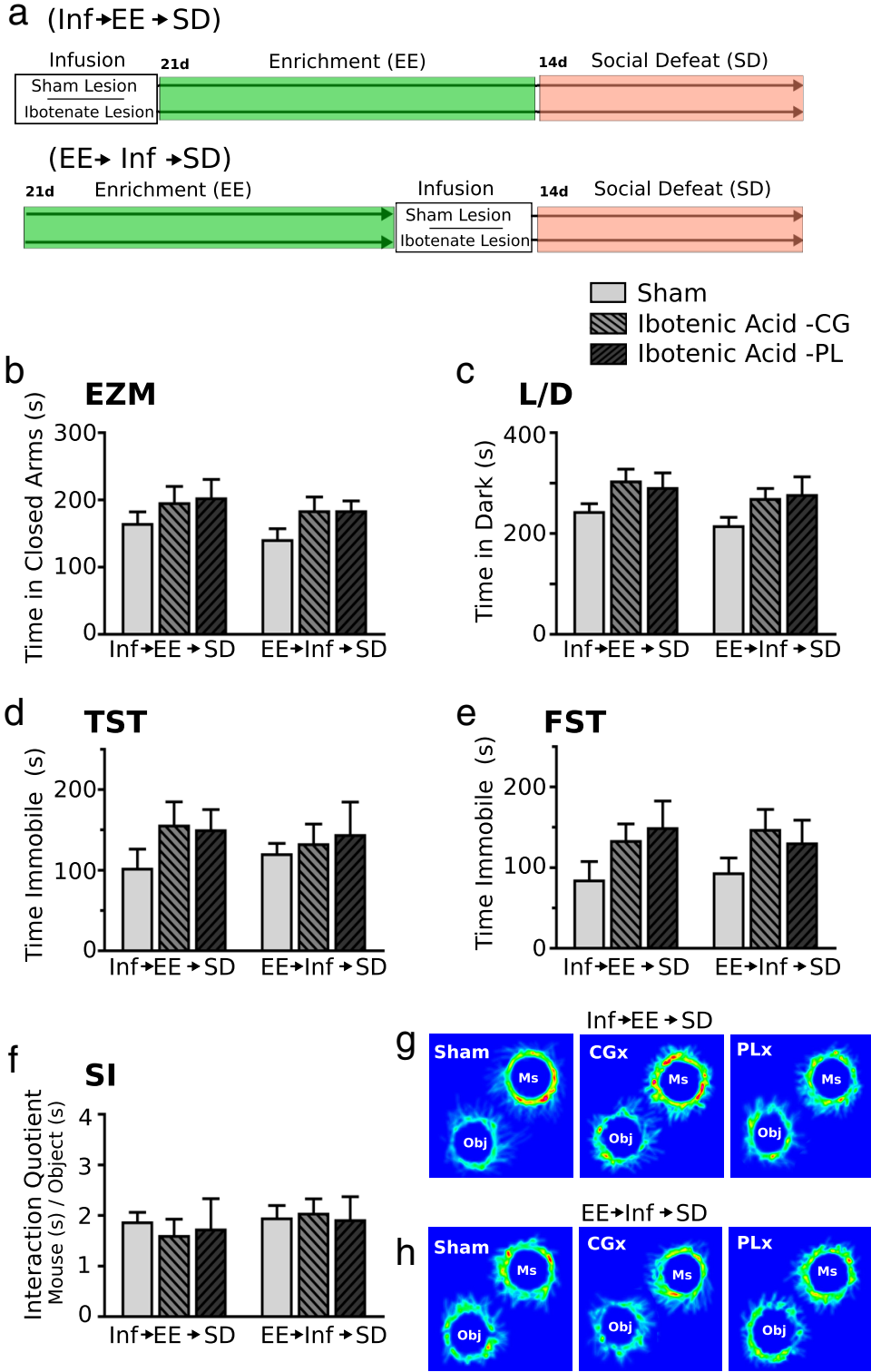

$\mathrm{EE} \rightarrow \operatorname{lnf} \rightarrow \mathrm{SD}$
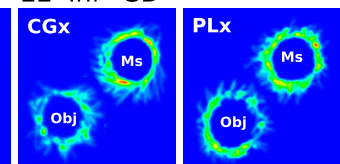

Figure 10. Lesions of $\mathrm{mPFC}$ neurons outside the IL have no effect on the acquisition or expression of resiliency after enriched forced-swim test (FST, $\boldsymbol{e})$, and social interaction task $(\mathrm{SI}, \boldsymbol{f}, \boldsymbol{g})(n=10$ per sham group, 6 per ibotenic acid-CG group, 5 per ibotenic acid-PL group). Inf, Infusion. Two-way ANOVA followed by Bonferroni's post hoc test.

stress-induced structural deficits in the $\mathrm{MPFC}$ and concomitant maladaptive behavioral responses may provide clues about the etiological basis of resiliency. For instance, in rodents, stress-induced volumetric decreases in $\mathrm{mPFC}$ and coincident maladaptive behaviors were reversed by antidepressant treatments (Bessa et al., 2009). In humans, studies by Mayberg and others have demonstrated consistent involvement of the subgenual cingulate cortex (BA25, comparable with the IL cortex in rodents) in acute sadness and in response to antidepressant treatment (Mayberg et al., 1999; Seminowicz et al., 2004) and deep brain stimulation (Mayberg et al., 2005; Lozano et al., 2008; McNeely et al., 2008).

The neurobiology and circuitry of resiliency

In humans and other animal species, physical exercise and positive psychosocial activities can improve cognitive function and reduce maladaptive behavioral responses to stress (Fox et al., 


\section{$\mathrm{PLx} \rightarrow \mathrm{EE} \rightarrow \mathrm{SD} \quad \mathrm{EE} \rightarrow \mathrm{PLx} \rightarrow \mathrm{SD}$}
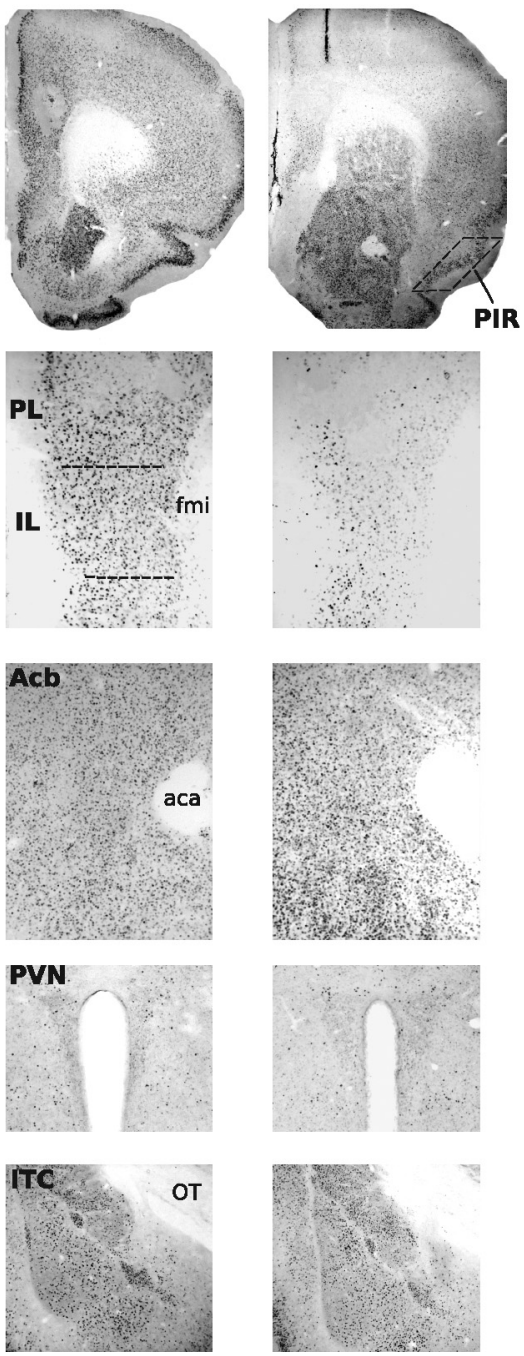
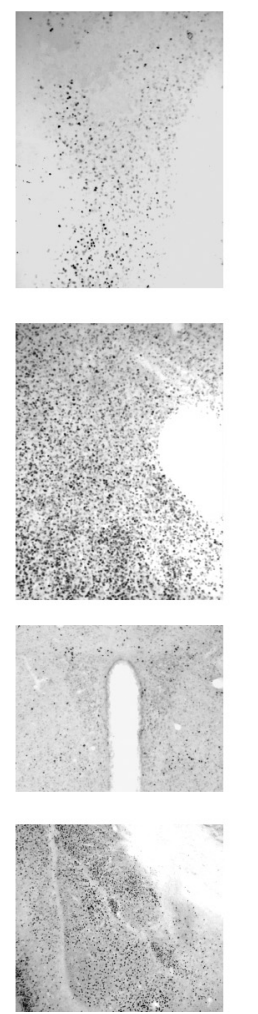

$\mathrm{CG} x \rightarrow \mathrm{EE} \rightarrow \mathrm{SD} \quad \mathrm{EE} \rightarrow \mathrm{CGx} \rightarrow \mathrm{SD}$
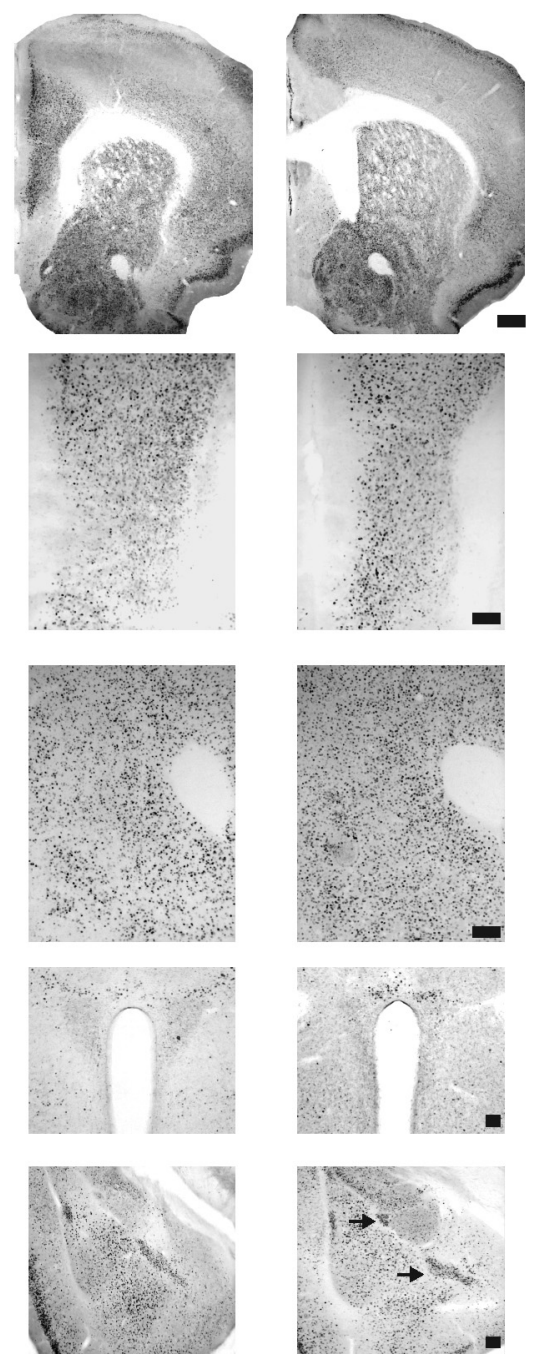

fear (Mueller et al., 2008; Quirk and Mueller, 2008) and strongly connects with other limbic cortices, nucleus accumbens, amygdala, midline thalamus, hypothalamus, and brainstem areas associated with stress neurocircuitry (Vertes, 2004). mPFC regulation of a fear response to a stimulus occurs through excitatory projections to GABAergic cell populations in the ITC or BLA (Vidal-Gonzalez et al., 2006; Peters et al., 2009; Sotres-Bayon and Quirk, 2010), thus inhibiting central nucleus output (Paré et al., 2004). Accordingly, stimulation of the IL cortex promotes extinction of conditioned fear (Milad and Quirk, 2002), whereas neurochemical IL inactivation (Santini et al., 2001) or stressinduced IL dendritic retraction produces deficits in fear extinction (Bessa et al., 2009), leading to anxiety disorders. In the current experiment, non-defeated EEhoused mice relative to IE mice showed enhanced FosB $/ \Delta$ FosB expression in the IL and its efferent targets. Interestingly, FosB $/ \Delta$ FosB expression was still observed in the IL cortex during SD exposure in mice previously housed in EE but not IE, suggesting that the IL cortex was still active during chronic stress. Furthermore, FosB $/ \Delta$ FosB expression in the ITC was positively correlated with expression in the IL cortex. The continued activation of the ILITC circuit during SD may explain the decreased display of anxiety and depressivelike behaviors observed in EE-SD mice. The observations that lesion of the IL cortex before EE abolished FosB/ $\Delta$ FosB expression in the ITC and also increased maladaptive behavioral responses to SD provide additional evidence that resiliency acquired by EE is mediated by IL activity. However, lesion of the IL cortex after EE did not degrade the expression of resiliency after $\mathrm{SD}$, suggesting that the role differences between defeated mice that received $\mathrm{CG}$ or PL lesions before enrichment ( $\mathrm{CGX} \rightarrow \mathrm{EE} \rightarrow \mathrm{SD}$ or $\mathrm{PLx} \rightarrow \mathrm{EE} \rightarrow \mathrm{SD}$, respectively) and defeated mice that received CG or PL lesions after enrichment ( $\mathrm{EE} \rightarrow \mathrm{CGX} \rightarrow \mathrm{SD}$ or $\mathrm{EE} \rightarrow \mathrm{PLx} \rightarrow \mathrm{SD}$, respectively) Dashed lines indicate templates within which counts were made. Black arrows point to ITC. For abbreviations, see Figure 2 legend. Scale bars: 400 and $100 \mu \mathrm{m}$ for low- and high-magnification photographs, respectively.

2006; Nithianantharajah and Hannan, 2006). Here we report that EE before SD blocks the deleterious effects of SD on social behavior and forced swim. Although the mechanisms by which EE may engender these resiliency effects are poorly understood, EE has the opposite effect of stress on biochemical and morphological measures such as dendritic spine density, neuronal morphology, hippocampal neurogenesis, and cortical neurotrophin expression (van Praag et al., 2000). Therefore, structural alterations resulting from EE may provide a reservoir of protection against the consequences of future stressors.

Comparative studies of mood and emotion under normal circumstances and during psychopathological conditions have started to define a model of resilience that integrates the neural circuitry known to mediate reward and fear extinction (Feder et al., 2009). Enhanced fear expression and the inability to extinguish emotional responses to conditioned fear can lead to maladaptive behaviors such as anxiety, panic, and PTSD (Myers and Davis, 2002; Heim and Nemeroff, 2009). The IL cortex is a key mediator of emotional responses associated with conditioned of the IL cortex in resiliency is context dependent. The continued expression of $\mathrm{FosB} / \Delta \mathrm{FosB}$ in the ITC in mice receiving IL lesions after EE suggests that these cell groups continue to remain active and possibly act to inhibit fear expression in the absence of IL inputs.

In contrast to fear extinction, reward is a reinforcing behavior that satisfies an appetitive drive. The accumbens is a critical element of the mesocorticolimbic system, a brain circuit implicated in reward and motivation (Koob and Le Moal, 2001). Multiple lines of evidence have suggested a strong relationship between Acb FosB $/ \Delta$ FosB expression and regulation of reward mechanisms and natural reward-related behavior (Werme et al., 2002; Teegarden et al., 2008; Wallace et al., 2008). For instance, genetic overexpression of $\Delta$ FosB in the Acb promotes appetitive and consummatory behavior (Werme et al., 2002; Olausson et al., 2006; Hedges et al., 2009). The current results show a strong correlation between $\mathrm{Acb}$ FosB $/ \Delta$ FosB expression and resiliency to $\mathrm{SD}$ and suggest that $\mathrm{FosB} / \Delta$ FosB expression in $\mathrm{Acb}$ during chronic stress enables an individual to enhance motivation and 
natural reward despite the ongoing stress. This idea is further supported by recent findings from Vialou et al. (2010) showing that resilience is mediated through $\Delta$ FosB in the Acb. In light of the present data, however, Acb FosB expression and stress resiliency appear to be gated by the IL cortex. The expression of FosB $/ \Delta$ FosB in the Acb during SD is strongly predicated on previous EE exposure and requires an intact IL cortex during EE exposure. Interestingly, however, the IL cortex is not required for the mediation of this effect during SD because IL lesioning after EE has no effect on Acb FosB expression or on SD resiliency. Rather it appears that alterations in IL output during EE drive molecular and structural changes in efferent target regions, and changes in these brain regions mediate the expression of stress resiliency.

\section{References}

Avgustinovich DF, Kovalenko IL, Kudryavtseva NN (2005) A model of anxious depression: persistence of behavioral pathology. Neurosci Behav Physiol 35:917-924.

Bessa JM, Ferreira D, Melo I, Marques F, Cerqueira JJ, Palha JA, Almeida OF, Sousa N (2009) The mood-improving actions of antidepressants do not depend on neurogenesis but are associated with neuronal remodeling. Mol Psychiatry 14:764-773, 739.

Bremner JD (2004) Brain imaging in anxiety disorders. Expert Rev Neurother 4:275-284.

Cerqueira JJ, Pêgo JM, Taipa R, Bessa JM, Almeida OF, Sousa N (2005) Morphological correlates of corticosteroid-induced changes in prefrontal cortex-dependent behaviors. J Neurosci 25:7792-7800.

Chapillon P, Manneché C, Belzung C, Caston J (1999) Rearing environmental enrichment in two inbred strains of mice. 1. Effects on emotional reactivity. Behav Genet 29:41-46.

Charney DS (2004) Psychobiological mechanisms of resilience and vulnerability: implications for successful adaptation to extreme stress. Am J Psychiatry 161:195-216.

Charney DS, Manji HK (2004) Life stress, genes, and depression: multiple pathways lead to increased risk and new opportunities for intervention. Sci STKE 2004:re5.

Chen J, Kelz MB, Hope BT, Nakabeppu Y, Nestler EJ (1997) Chronic Fosrelated antigens: stable variants of $\triangle \mathrm{FosB}$ induced in brain by chronic treatments. J Neurosci 17:4933-4941.

Feder A, Nestler EJ, Charney DS (2009) Psychobiology and molecular genetics of resilience. Nat Rev Neurosci 10:446-457.

Fox C, Merali Z, Harrison C (2006) Therapeutic and protective effect of environmental enrichment against psychogenic and neurogenic stress. Behav Brain Res 175:1-8.

Franklin KBJ, Paxinos G (1997) The mouse brain in stereotaxic coordinates. San Diego: Academic.

Greenwood BN, Fleshner M (2008) Exercise, learned helplessness, and the stress-resistant brain. Neuromolecular Med 10:81-98.

Hedges VL, Chakravarty S, Nestler EJ, Meisel RL (2009) Delta FosB overexpression in the nucleus accumbens enhances sexual reward in female Syrian hamsters. Genes Brain Behav 8:442-449.

Heim C, Nemeroff CB (2009) Neurobiology of posttraumatic stress disorder. CNS Spectr 14:13-24.

Holmes A, Wellman CL (2009) Stress-induced prefrontal reorganization and executive dysfunction in rodents. Neurosci Biobehav Rev 33:773-783.

Huhman KL (2006) Social conflict models: can they inform us about human psychopathology? Horm Behav 50:640-646.

Hurley KM, Herbert H, Moga MM, Saper CB (1991) Efferent projections of the infralimbic cortex of the rat. J Comp Neurol 308:249-276.
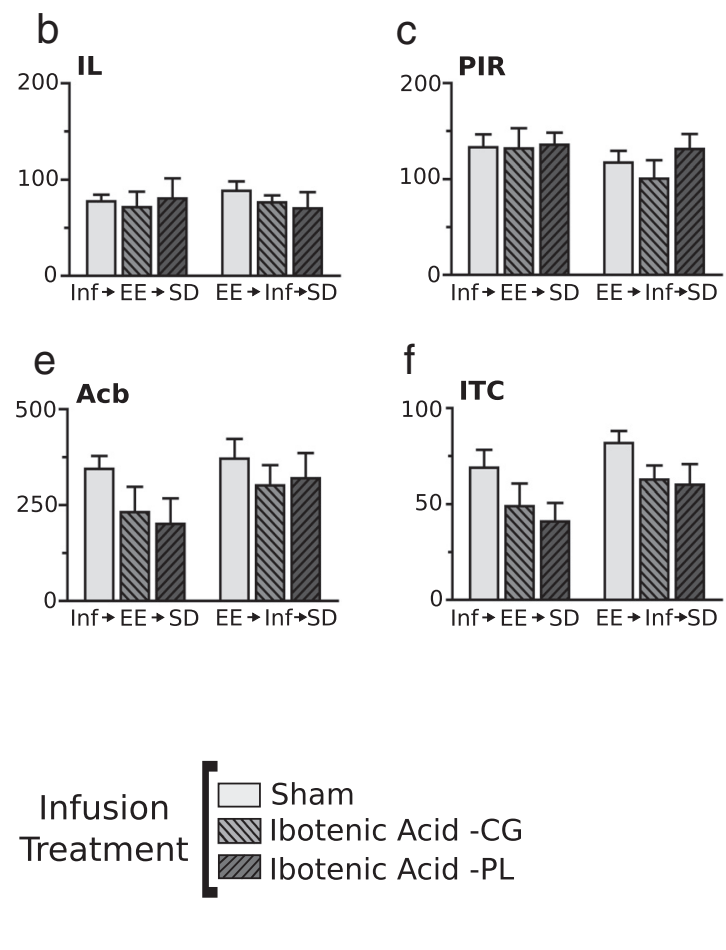
following lesions of the prelimbic or infralimbic cortex in the rat. Brain Res 772:181-190.

Koob GF, Le Moal M (2001) Drug addiction, dysregulation of reward, and allostasis. Neuropsychopharmacology 24:97-129.

Koolhaas JM, De Boer SF, De Rutter AJ, Meerlo P, Sgoifo A (1997) Social stress in rats and mice. Acta Physiol Scand Suppl 640:69-72.

Krishnan V, Han MH, Graham DL, Berton O, Renthal W, Russo SJ, Laplant Q, Graham A, Lutter M, Lagace DC, Ghose S, Reister R, Tannous P, Green TA, Neve RL, Chakravarty S, Kumar A, Eisch AJ, Self DW, Lee FS, et al. (2007) Molecular adaptations underlying susceptibility and resistance to social defeat in brain reward regions. Cell 131:391-404.

Kudryavtseva NN (2000) Agonistic behavior: a model, experimental studies, and perspectives. Neurosci Behav Physiol 30:293-305.

Kudryavtseva NN, Avgustinovich DF (1998) Behavioral and physiological markers of experimental depression induced by social conflicts (DISC). Aggress Behav 24:271-286.

Lacroix L, Broersen LM, Weiner I, Feldon J (1998) The effects of excitotoxic lesion of the medial prefrontal cortex on latent inhibition, prepulse inhibition, food hoarding, elevated plus maze, active avoidance and locomotor activity in the rat. Neuroscience 84:431-442.

Lozano AM, Mayberg HS, Giacobbe P, Hamani C, Craddock RC, Kennedy SH (2008) Subcallosal cingulate gyrus deep brain stimulation for treatment-resistant depression. Biol Psychiatry 64:461-467.

Luger A, Deuster PA, Kyle SB, Gallucci WT, Montgomery LC, Gold PW, Loriaux DL, Chrousos GP (1987) Acute hypothalamic-pituitary-adrenal responses to the stress of treadmill exercise. Physiologic adaptations to physical training. N Engl J Med 316:1309-1315.

Lyons DM, Parker KJ (2007) Stress inoculation-induced indications of resilience in monkeys. J Trauma Stress 20:423-433.

Mayberg HS, Liotti M, Brannan SK, McGinnis S, Mahurin RK, Jerabek PA, Silva JA, Tekell JL, Martin CC, Lancaster JL, Fox PT (1999) Reciprocal limbic-cortical function and negative mood: converging PET findings in depression and normal sadness. Am J Psychiatry 156:675-682.

Mayberg HS, Lozano AM, Voon V, McNeely HE, Seminowicz D, Hamani C, Schwalb JM, Kennedy SH (2005) Deep brain stimulation for treatmentresistant depression. Neuron 45:651-660. 

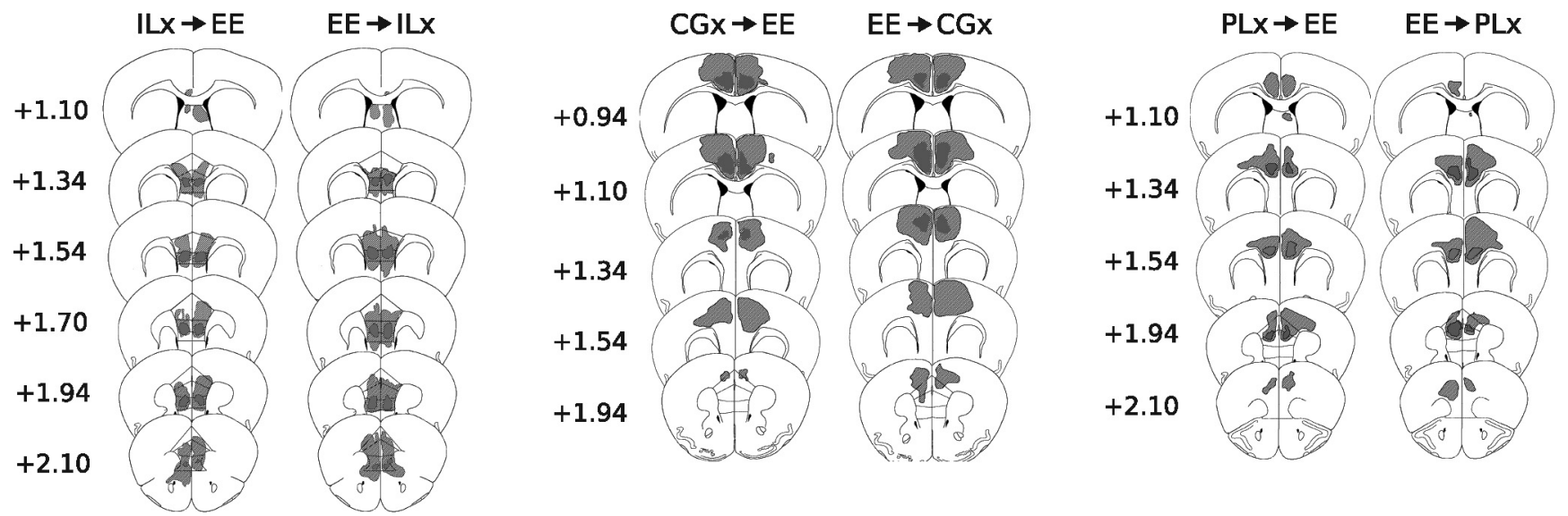

Figure 13. A schematic representation depicting reconstruction of lesions in IL, CG, or PL from mice that received lesions before or after enriched housing. Drawings of coronal sections, modified from the atlas of Franklin and Paxinos (1997), are oriented by distance from bregma. The maximal extent of the lesion is shown in light gray, and the overlap of all lesions is shown in black.

McClung CA, Ulery PG, Perrotti LI, Zachariou V, Berton O, Nestler EJ (2004) DeltaFosB: a molecular switch for long-term adaptation in the brain. Brain Res Mol Brain Res 132:146-154.

Mcdonald AJ, Mascagni F, Guo L (1996) Projections of the medial and lateral prefrontal cortices to the amygdala: a Phaseolus vulgaris leucoagglutinin study in the rat. Neuroscience 71:55-75.

McEwen BS, Stellar E (1993) Stress and the individual. Mechanisms leading to disease. Arch Intern Med 153:2093-2101.

McNeely HE, Mayberg HS, Lozano AM, Kennedy SH (2008) Neuropsychological impact of Cg25 deep brain stimulation for treatment-resistant depression: preliminary results over 12 months. J Nerv Ment Dis 196:405-410.

Milad MR, Quirk GJ (2002) Neurons in medial prefrontal cortex signal memory for fear extinction. Nature 420:70-74.

Mueller D, Porter JT, Quirk GJ (2008) Noradrenergic signaling in infralimbic cortex increases cell excitability and strengthens memory for fear extinction. J Neurosci 28:369-375.

Myers KM, Davis M (2002) Behavioral and neural analysis of extinction. Neuron 36:567-584.

Nithianantharajah J, Hannan AJ (2006) Enriched environments, experiencedependent plasticity and disorders of the nervous system. Nat Rev Neurosci 7:697-709.

Olausson P, Jentsch JD, Tronson N, Neve RL, Nestler EJ, Taylor JR (2006) $\Delta$ FosB in the nucleus accumbens regulates food-reinforced instrumental behavior and motivation. J Neurosci 26:9196-9204.

Paré D, Quirk GJ, Ledoux JE (2004) New vistas on amygdala networks in conditioned fear. J Neurophysiol 92:1-9.

Perrotti LI, Hadeishi Y, Ulery PG, Barrot M, Monteggia L, Duman RS, Nestler EJ (2004) Induction of deltaFosB in reward-related brain structures after chronic stress. J Neurosci 24:10594-10602.

Peters J, Kalivas PW, Quirk GJ (2009) Extinction circuits for fear and addiction overlap in prefrontal cortex. Learn Mem 16:279-288.

Price JL, Drevets WC (2010) Neurocircuitry of mood disorders. Neuropsychopharmacology 35:192-216.

Quirk GJ, Mueller D (2008) Neural mechanisms of extinction learning and retrieval. Neuropsychopharmacology 33:56-72.

Radley JJ, Arias CM, Sawchenko PE (2006) Regional differentiation of the medial prefrontal cortex in regulating adaptive responses to acute emotional stress. J Neurosci 26:12967-12976.

Salmon P (2001) Effects of physical exercise on anxiety, depression, and sensitivity to stress: a unifying theory. Clin Psychol Rev 21:33-61.

Santini E, Muller RU, Quirk GJ (2001) Consolidation of extinction learning involves transfer from NMDA-independent to NMDA-dependent memory. J Neurosci 21:9009-9017.

Sapolsky RM (2000) Glucocorticoids and hippocampal atrophy in neuropsychiatric disorders. Arch Gen Psychiatry 57:925-935.

Sasse SK, Greenwood BN, Masini CV, Nyhuis TJ, Fleshner M, Day HE, Campeau S (2008) Chronic voluntary wheel running facilitates corticosterone response habituation to repeated audiogenic stress exposure in male rats. Stress 11:425-437.
Schloesser RJ, Lehmann M, Martinowich K, Manji HK, Herkenham M (2010) Environmental enrichment requires adult neurogenesis to facilitate the recovery from psychosocial stress. Mol Psychiatry 15:1152-1163.

Seminowicz DA, Mayberg HS, McIntosh AR, Goldapple K, Kennedy S, Segal Z, Rafi-Tari S (2004) Limbic-frontal circuitry in major depression: a path modeling metanalysis. Neuroimage 22:409-418.

Sesack SR, Deutch AY, Roth RH, Bunney BS (1989) Topographical organization of the efferent projections of the medial prefrontal cortex in the rat: an anterograde tract-tracing study with Phaseolus vulgaris leucoagglutinin. J Comp Neurol 290:213-242.

Sotres-Bayon F, Quirk GJ (2010) Prefrontal control of fear: more than just extinction. Curr Opin Neurobiol 20:231-235.

Southwick SM, Vythilingam M, Charney DS (2005) The psychobiology of depression and resilience to stress: implications for prevention and treatment. Annu Rev Clin Psychol 1:255-291.

Stone EA, Yan L, Ahsan MR, Lehmann ML, Yeretsian J, Quartermain D (2006) Role of CNS alpha1-adrenoceptor activity in central fos responses to novelty. Synapse 59:299-307.

Stone EA, Lehmann ML, Lin Y, Quartermain D (2007) Reduced evoked fos expression in activity-related brain regions in animal models of behavioral depression. Prog Neuropsychopharmacol Biol Psychiatry 31:1196-1207.

Suomi SJ (2006) Risk, resilience, and gene x environment interactions in rhesus monkeys. Ann N Y Acad Sci 1094:52-62.

Teegarden SL, Nestler EJ, Bale TL (2008) Delta FosB-mediated alterations in dopamine signaling are normalized by a palatable high-fat diet. Biol Psychiatry 64:941-950.

van Praag H, Kempermann G, Gage FH (2000) Neural consequences of environmental enrichment. Nat Rev Neurosci 1:191-198.

Vertes RP (2004) Differential projections of the infralimbic and prelimbic cortex in the rat. Synapse 51:32-58.

Vialou V, Robison AJ, Laplant QC, Covington HE 3rd, Dietz DM, Ohnishi YN, Mouzon E, Rush AJ 3rd, Watts EL, Wallace DL, Iñiguez SD, Ohnishi YH, Steiner MA, Warren BL, Krishnan V, Bolaños CA, Neve RL, Ghose S, Berton O, Tamminga CA, Nestler EJ (2010) DeltaFosB in brain reward circuits mediates resilience to stress and antidepressant responses. Nat Neurosci 13:745-752.

Vidal-Gonzalez I, Vidal-Gonzalez B, Rauch SL, Quirk GJ (2006) Microstimulation reveals opposing influences of prelimbic and infralimbic cortex on the expression of conditioned fear. Learn Mem 13:728-733.

Wallace DL, Vialou V, Rios L, Carle-Florence TL, Chakravarty S, Kumar A, Graham DL, Green TA, Kirk A, Iñiguez SD, Perrotti LI, Barrot M, DiLeone RJ, Nestler EJ, Bolaños-Guzmán CA (2008) The influence of $\Delta$ FosB in the nucleus accumbens on natural reward-related behavior. J Neurosci 28:10272-10277.

Werme M, Messer C, Olson L, Gilden L, Thorén P, Nestler EJ, Brené S (2002) $\Delta$ FosB regulates wheel running. J Neurosci 22:8133-8138.

Wittert GA, Livesey JH, Espiner EA, Donald RA (1996) Adaptation of the hypothalamopituitary adrenal axis to chronic exercise stress in humans. Med Sci Sports Exerc 28:1015-1019. 